Aus der Klinik Nephrologie und Rheumatologie

(Prof. Dr. med. G. A. Müller)

der Medizinischen Fakultät der Universität Göttingen

\title{
Der langfristige Effekt einer RAAS- \\ Blockade auf den Krankheitsverlauf bei \\ heterozygoten Mutationsträgern des \\ Alport-Syndroms
}

Eine prospektive Vier-Jahres-Auswertung des Europäischen

Alport-Registers

\author{
INAUGURAL-DISSERTATION \\ zur Erlangung des Doktorgrades \\ der Medizinischen Fakultät der \\ Georg-August-Universität zu Göttingen
}

vorgelegt von

Johannes Künanz

aus

Friedrichroda 
Dekan:

Referent/in

Ko-Referent/in:
Prof. Dr. Wolfgang Brück

Prof. Dr. Oliver Gross

PD Dr. Hendrik Rosewich

Datum der mündlichen Prüfung: 19.02 .2020 
Hiermit erkläre ich, die Dissertation mit dem Titel „Der langfristige Effekt einer RAAS-Blockade auf den Krankheitsverlauf bei beterozygoten Mutationsträgern des Alport-Syndroms - Eine prospektive VierJahres-Auswertung des Europäischen Alport-Registers" eigenständig angefertigt und keine anderen als die von mir angegebenen Quellen und Hilfsmittel verwendet zu haben.

Göttingen, den 01.09.2018 


\section{Inhaltsverzeichnis}

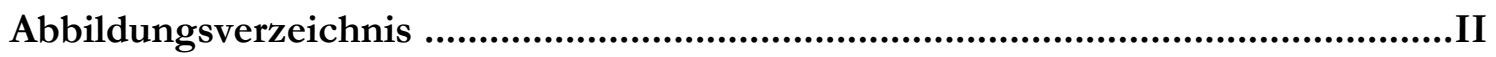

Tabellenverzeichnis ......................................................................................... III

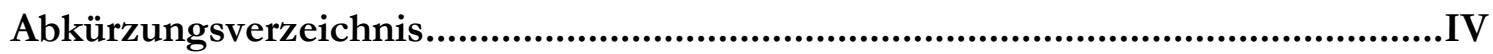

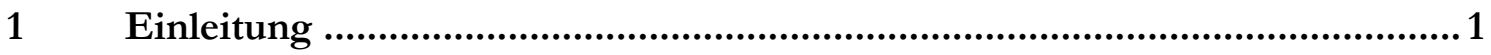

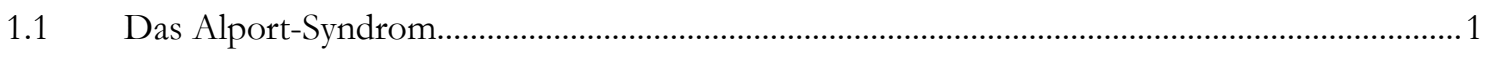

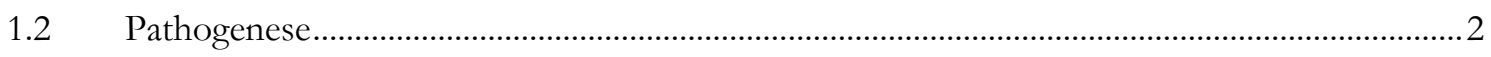

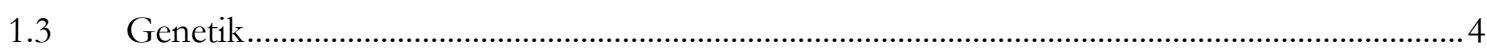

$1.4 \quad$ Klinisches Erscheinungsbild.........................................................................................

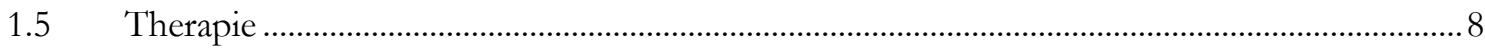

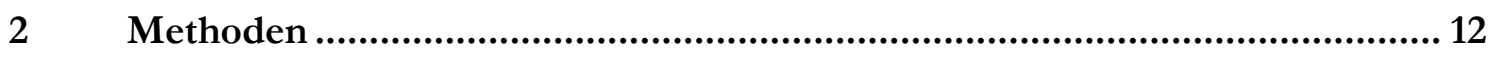

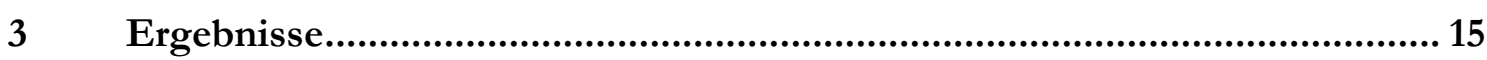

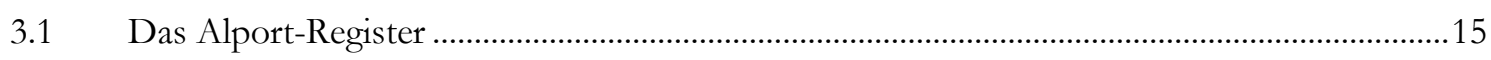

3.1.1 Auswertung des aktualisierten Alport-Registers.....................................................................16

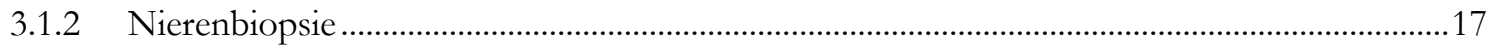

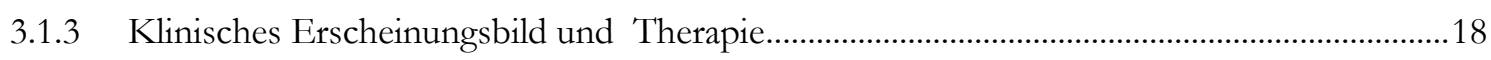

3.1.4 Symptome bei Erkrankungsbeginn und Dauer bis zur Diagnosestellung.................................20

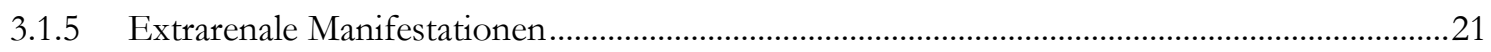

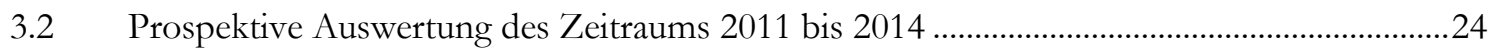

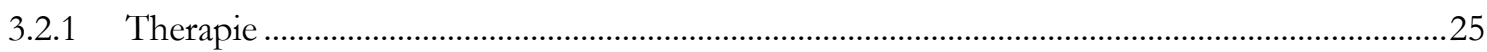

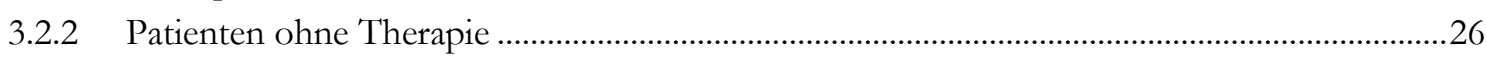

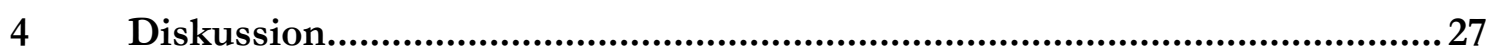

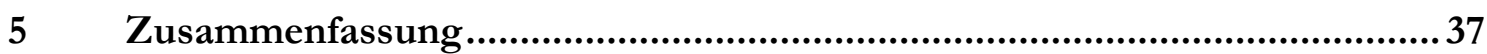

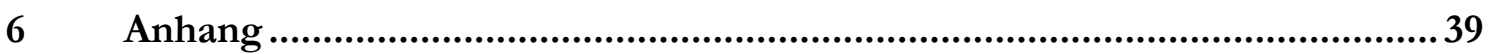

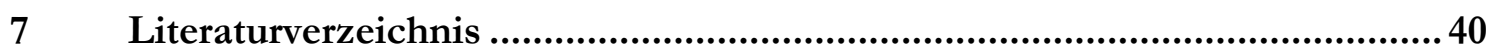




\section{Abbildungsverzeichnis}

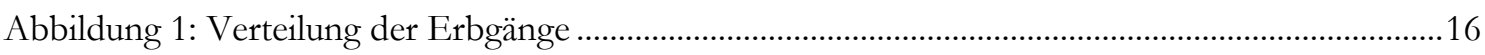

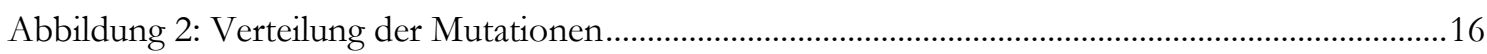

Abbildung 3: Vergleich der Vererbungsmuster in Bezug auf den Endpunkt RRT .............................17

Abbildung 4: Patientenverteilung bezogen auf den Therapiebeginn ......................................................18

Abbildung 5: Kaplan-Meier-Schätzer der unter ACEi-Therapie stehenden Patienten ..........................20

Abbildung 6: Kaplan-Meier-Schätzer der Patienten mit Schwerhörigkeit .............................................22

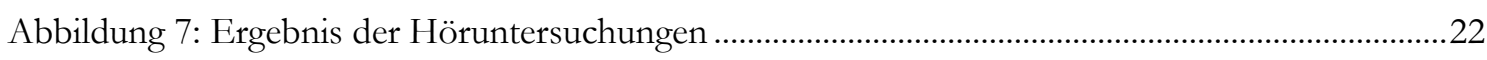

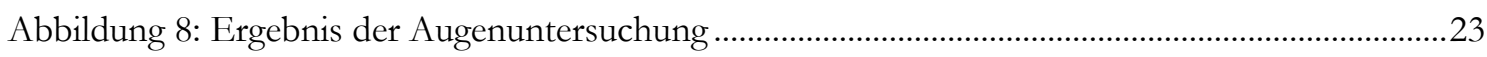

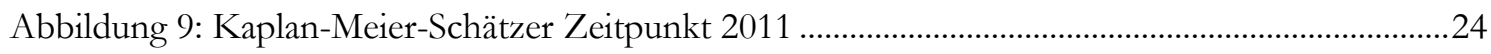

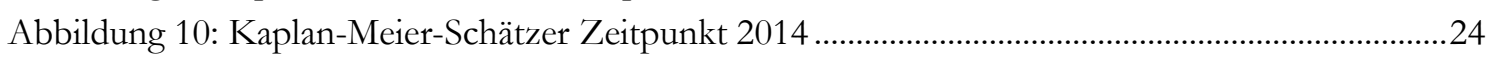

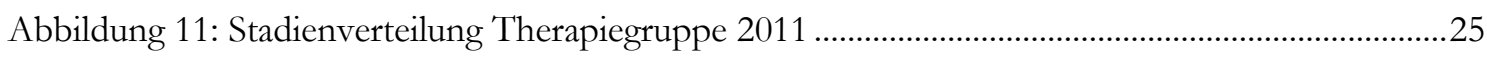

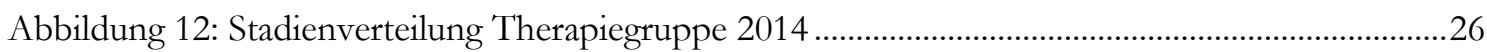

Abbildung 13: Stadienvergleich der Stichjahre 2011/2014 Gruppe ohne Therapie (kT) ....................26

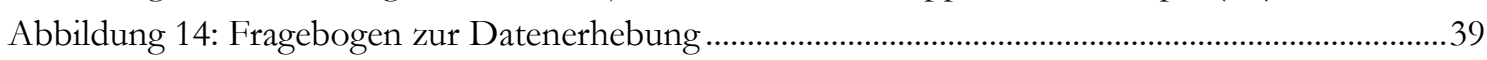




\section{Tabellenverzeichnis}

Tabelle 1: Exprimierung der sechs bekannten $\alpha$-Ketten (modifiziert nach Kashtan 1999) ..................3

Tabelle 2: Aufteilung der Patienten auf die bundesweiten 14 Standorte................................................15

Tabelle 3: Übersicht über die Therapiehäufigkeit..............................................................................19

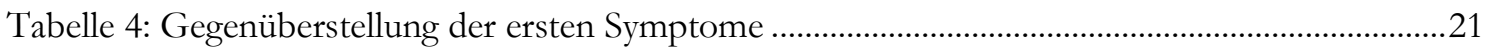

Tabelle 5: Deskriptive Auswertung der extrarenalen Symptome.........................................................23 


\section{Abkürzungsverzeichnis}

$\begin{array}{ll}\text { ACEi } & \text { ACE-Hemmer } \\ \text { ARAS } & \text { autosomal-rezessives Alport-Syndrom } \\ \text { AS } & \text { Alport-Syndrom } \\ \text { AT1 } & \text { Angiotensin-II-Rezeptor-Subtyp-1 } \\ \text { COL4 } & \text { Kollagen Typ IV } \\ \text { eNaC } & \text { epithelial Na-channel } \\ \text { ESRD } & \text { endstage renal disease } \\ \text { FSGS } & \text { fokal-segmentale Glomerulosklerose } \\ \text { GBM } & \text { glomeruläre Basal-Membran } \\ \text { GFR } & \text { glomeruläre Filtrationsrate } \\ \text { kT } & \text { keine Therapie } \\ \text { MMP } & \text { Matrix-Metallo-Proteinasen } \\ \text { NFKB } & \text { nuclear factor'kappa-light-chain-enhancer' of activated B-cells } \\ \text { NI } & \text { Niereninsuffizienz } \\ \text { RAAS } & \text { Renin-Angiotensin-Aldosteron-System } \\ \text { RRT } & \text { renal replacement therapy } \\ \text { TBMN } & \text { thin basement membrane nephropathy } \\ \text { TGF } \beta & \text { transforming growth factor beta } \\ \text { XLAS } & \text { X chromosomal-linked Alport syndrome }\end{array}$




\section{$1 \quad$ Einleitung}

\subsection{Das Alport-Syndrom}

Das Alport-Syndrom (kurz: AS) ist eine progrediente hereditäre Nierenerkrankung, die mit einer Hämaturie, fortschreitender Niereninsuffizienz, Innenohrschwerhörigkeit und typischen Augenveränderungen einhergeht (Kruegel et al. 2013). Das AS beruht auf Mutationen in den Genen, welche für das Kollagen Typ IV codieren. Dadurch kommt es zu fehlerhaft ausgebildeten Kollagenketten, die ihre Funktion als wesentlicher Bestandteil der glomerulären Basalmembran (kurz: GBM) verlieren. Im Jahr 1927 stellte A.C. Alport erstmals den Zusammenhang zwischen Patienten mit Hämaturie und Schwerhörigkeit fest (Alport 1927). Er analysierte eine Familie, die A.Hurst bereits 1923 aufgrund gehäuften Vorkommens einer Hämaturie beschrieben hatte (Hurst 1923). Alport fiel eine zusätzliche Häufung von Fällen mit Schwerhörigkeit in dieser Familie auf. Auch berichtete er über einen Fall mit einer Augenveränderung (Alport 1927). Nach dem Tode Alports wurde die Trias "familiäre Hämaturie - Schwerhörigkeit - Augenveränderung" nach ihm benannt.

Erst in den 70er Jahren des 20. Jahrhunderts konnte mittels der Elektronenmikroskopie ein Zusammenhang zwischen der Klinik des AS und den pathogenetischen Veränderungen in Form einer Aufsplitterung und Verdickung der glomerulären Basalmembran erbracht werden (Hinglais et al. 1972; Churg und Sherman 1973). Schließlich konnten 1990 von Barker et al. Mutationen in der $\alpha$-Kette des Kollagen(IV) identifiziert werden, welche im Zusammenhang mit den am Alport-Syndrom erkrankten Personen standen(Barker et al. 1990). Mittlerweile sind über 600 Mutationen bekannt, die zu einer Mutation des Kollagen (IV) führen (Hertz et al. 2012).

Es wird davon ausgegangen, dass in den USA 2,5\% der dialysepflichtigen Patienten am AS erkrankt sind. In Europa beläuft sich diese Zahl schätzungsweise auf 0,64\% (Meroni und Sessa 2013). Das AS zählt somit zu den selteneren hereditären Krankheiten. Es wird für das X-chromosomal vererbte AS (XLAS) von einer Prävalenz von 1:10000 und bei dem autosomal vermittelten AS von 1:50000 ausgegangen (Hertz 2009). In einigen Regionen in den USA wie Utah wird eine Prävalenz von etwa 1:5000 angegeben (Hasstedt und Atkin 1983).

Das Alport-Ssyndrom wird in 80-85\% der Fälle X-chromosomal vererbt. Bei 15\% der Erkrankten liegt ein autosomal-rezessiver Erbgang vor (Hertz et al. 2012). Aufgrund des Vererbungsmusters ist vor allem das männliche Geschlecht betroffen (Hudson et al. 2003; Hertz et al. 2012). Ein autosomal-dominanter Erbgang (kurz: AD) ist bisher nur in vereinzelten Familien beschrieben und wurde bisher als sehr selten eingestuft. Diese Annahme könnte unterschätzt sein, denn Daten aus neuesten Next-Generation- 
Sequencing-Methoden scheinen ein höheres Vorkommen des AD-Erbganges zu belegen (Morinière et al. 2014).

In der vorliegenden Arbeit wird der Einfluss einer RAAS-Blockade auf das Fortschreiten der Erkrankung bei heterozygoten Patientinnen und Patienten untersucht. Dies betrifft einerseits Frauen mit dem XLAS und andererseits beide Geschlechter, wenn ein heterozygot autosomal-rezessiver Erbgang vorliegt. Carrier und somit vor allem weibliche Patienten waren lange Zeit nicht Hauptmerkmal der Untersuchungen zum AlportSsyndrom und werden in der Literatur oft als benigne Carrier charakterisiert. Bereits Alport stellte fest: "The female have deafness and haematuria and live to old age"(Alport 1927, S.506).

Zwar weisen viele der Carrier im Laufe ihres Lebens nur eine Hämaturie auf, dennoch treten auch bei heterozygoten Mutationsträgern Krankheitsverläufe bis hin zum Nierenversagen auf, obwohl diese deutlich seltener sind (Jais 2003). Des Weiteren fällt die Diagnostik der Carrier aufgrund der weiten Spanne von Symptomen schwer. Oft wird eine weiterführende Diagnostik erst dann veranlasst, wenn zum Beispiel ein vom AS betroffener Sohn geboren wird oder es im Rahmen von Infekten oder einer Schwangerschaft zu einer passageren Proteinurie oder Makrohämaturie kommt. So wird die Diagnose AlportSyndrom bei den Carriern oft erst im frühen Erwachsenenalter gestellt. Dabei zeigen klinische Verlaufsbeobachtungen, dass auch Carrier von einer effizienten und rechtzeitigen Therapie profitieren können, unabhängig vom Risiko einen fulminanten Verlauf des AS zu entwickeln (Temme et al. 2012).

Dieser Arbeit zugrunde liegt die Auswertung einer größeren Kohorte von heterozygoten Mutationsträgern aus dem Europäischen Alport-Register, das O. Gross vor etwa 15 Jahren etablierte (Gross et al. 2012b). Das Hauptanliegen meiner Arbeit ist es, in einem prospektiven Verlauf die Krankheitsentwicklung der Carrier mit und ohne Therapie mittels der Blockade des Renin-Angiotensin-Aldosteron-Systems (kurz: RAAS) zu untersuchen. Weitere Daten zu den extrarenalen Manifestationen und Diagnostikkriterien des AS wurden ausgewertet, um Effekte und Ausprägungen bei den heterozygoten Mutationsträgern $\mathrm{zu}$ erfassen. Ziel dieser Untersuchung ist es, Therapieeffekte noch deutlicher aufzuweisen und die klinische Entwicklung der Carrier besser zu verstehen.

\subsection{Pathogenese}

Die renale Symptomatik des AS geht mit einer Störung der glomerulären Filtrationseinheit einher. Kernstücke des Filtrationsmechanismus sind ein fenestriertes Endothel, die glomeruläre Basalmembran und spezialisierte Zellen, die Podozyten. Diese liegen mit ihren Zellfortsätzen der Basalmembran auf. Sie lassen kleinste Spalträume frei, welche von einer extrazellulären Schicht, der Schlitzmembran, überdeckt werden. Die für die AlportErkrankung entscheidende Struktur ist die GBM. Sie hat einen entscheidenden Anteil an dem Filtrationsprozess. An ihrem Aufbau beteiligt sind Laminine, Heparansulfat, 
Fibronektin und vor allem Kollagenfasern vom Typ IV (Abrahamson et al. 2009; Miner 1999).

Die kleinste Baueinheit des Kollagen (IV)-Netzwerkes bilden Monomere aus $\alpha$-Ketten, von denen sechs bekannt sind: $\alpha 1$ bis $\alpha 6$ (vgl. Tab. 1). Es können sich jedoch nur folgende Triple ausbilden: $\alpha 1 . \alpha 1 . \alpha 2-\alpha 3 . \alpha 4 . \alpha 5-\alpha 5 . \alpha 5 . \alpha 6$. Die jeweiligen $\alpha$-Ketten weisen alle dasselbe Grundgerüst auf. Die Primärstruktur bildet eine sich wiederholende Aminosäurekette, welche immer einen festen Anteil an Glycin besitzt und durch zwei weitere Aminosäuren ergänzt wird. Diese GLY-X-Y-Sequenz wiederholt sich 1400-mal und bildet so den Kollagenanteil der $\alpha$-Ketten aus. Ergänzend bilden nicht-kollagenöse Strukturen eine aminoterminale (N-NC) und carboxyterminale (NC1) Domäne aus. (Hudson et al. 1993; Prockop 1995).

Die verschiedenen $\alpha$-Ketten werden in verschiedenen Organen exprimiert (Tab. 1).

Tabelle 1: Exprimierung der sechs bekannten $\alpha$-Ketten (modifiziert nach Kashtan 1999)

\begin{tabular}{|l|l|l|l|}
\hline$\alpha$-Kette & Gen & Chromosom & Vorkommen \\
\hline \hline$\alpha 1$ & COL4A1 & 2 & alle Basalmembranen \\
\hline$\alpha 2$ & COL4A2 & 2 & alle Basalmembranen \\
\hline$\alpha 3$ & COL4A3 & 13 & Niere, Auge, Ohr \\
\hline$\alpha 4$ & COL4A4 & 13 & Niere, Auge, Ohr \\
\hline$\alpha 5$ & COL4A5 & $\mathrm{X}$ & Niere, Auge, Ohr \\
\hline$\alpha 6$ & COL4A6 & $\mathrm{X}$ & $\begin{array}{l}\text { Niere, Auge?, Ohr?, } \\
\text { Haut }\end{array}$ \\
\hline
\end{tabular}

Aus jeweils drei $\alpha$-Ketten formen sich als Triple-Helices angeordnete Protomere.

Die entstandenen Protomere verknüpfen sich jeweils paarig über die NC1-Domäne, wodurch Hexamere entstehen. Über die Amino-Domäne verknüpfen sich jeweils vier Protomere und bilden ein Tetramer aus. Letztendlich entsteht so ein dichtes Kollagennetz. In der GBM nehmen die Podozyten eine entscheidende Rolle ein, da sie die $\alpha 3 . \alpha 4 . \alpha 5$ Protomere produzieren. Dagegen werden die $\alpha 1 . \alpha 1 . \alpha 2$-Protomere der GBM von Endothelzellen, Mesangialzellen und Podozyten hergestellt (Abrahamson et al. 2009). Das Kollagennetz bildet die Grundlage für die Einlagerung von anderen Bestandteilen der Basalmembran und der Zellanheftung und sorgt so für eine dreidimensionale Stabilität (Kashtan 1999).

Beim AS führen Mutationen der $\alpha$-Ketten zu fehlerhaften Verknüpfungen der Protomere oder zu einem Abknicken der Helices und dadurch zu einem fehlerhaften Aufbau des Kollagennetzes (Prockop 1990). Davon betroffen sind die $\alpha 3$-, $\alpha 4$ - und $\alpha 5$ - Kollagenketten. Eine weitere Interaktion findet über den Discoidin-Domain-Rezeptor 1 und über $\alpha 2 \beta 1$ - 
Integrin statt (Gross et al. 2004; Vogel et al. 1997; Barczyk et al. 2010). Diese scheint beim AS gestört zu sein (Kruegel et al. 2013).

In der embryonalen Ausbildung der Niere erfolgt ein Isotypwechsel der $\alpha$-Ketten (Kalluri et al. 1997). Die embryonale GBM besteht ausschließlich aus $\alpha 1$ und $\alpha 2$ Kollagen-IV. Bei der Ausbildung der adulten Niere kommt es normalerweise zu einem Wechsel der juvenilen Alphaketten hin zu $\alpha(3-5)$ Ketten. Diese sind im Vergleich zu den $\alpha 1$ - und $\alpha 2-$ Ketten vermehrt durch Disulfidbrücken verknüpft und dadurch stabiler in Bezug auf den Filtrationsdruck und den proteolytischen Stress (Noone und Licht 2013; Hudson et al. 2003).

Beim AS wird eine Persistenz der embryonalen Kettenstrukturen beobachtet, da die durch Mutationen fehlerhaft ausgebildeten $\alpha 3-\alpha 5$ Ketten funktionslos sind und degradieren. So sind die weniger resistenten $\alpha 1$ - und $\alpha 2$ - Ketten dem mit der Ausbildung der adulten Niere steigenden Filtrationsdruck sowie vermehrtem oxydativen Stress ausgesetzt. Die Suszeptibilität dieser Ketten auf endoproteolytische Mechanismen sind erhöht (Kalluri et al. 1997). Dabei spielen verschiedene Formen von Matrix-Metalloproteinasen (kurz: MMP) eine wichtige Rolle. In Tierstudien wurde festgestellt, dass verschiedene Subtypen in Alport-Mäusen deutlich erhöht sind (Cosgrove 2012). Dies hat zur Folge, dass über eine vermehrte Anreicherung von glomerulärer Matrix eine gesteigerte Fibrosierung stattfindet.

Ein weiterer Faktor, der zu einem fortschreitenden Filtrationsdefekt führt, ist die Überexpression von atypischen Lamininisoformen im Sinne eines Kompensationsmechanismus (Abrahamson et al. 2003). Des Weiteren kommt es zu einer gesteigerten Produktion von TGFß1, welches im Zusammenhang mit einer Entzündungsreaktion im Sinne einer Glomerulopathie steht. Es wird davon ausgegangen, dass die atypische Lamininexpression zu einer pathologischen Permeabilität der Basalmembran führt (Abrahamson et al. 2007).

Die vermehrte Anreicherung von extrazellulärer Matrix führt zu einer Fibrosierung der GBM (Noone und Licht 2013; Hudson 2004). Dieser Prozess wird durch eine epithelialmesenchymale Transformation, wie sie im Rahmen der Nierenfibrose beschrieben ist, beschleunigt (Liu 2010).

Als Folge kommt es im Laufe der Zeit zu einer zunehmenden Insuffizienz der GBM mit einhergehender Proteinurie und Abnahme der Kreatinin-Clearance.

\subsection{Genetik}

Die X-chromosomale Vererbung des AS (kurz: XLAS) kommt mit etwa 85\%, gefolgt von der autosomal-rezessiven Variante des AS (kurz: ARAS) mit $15 \%$, am häufigsten vor (Hudson et al. 2003; Hertz et al. 2012). In nur einigen Familien wird der sehr seltene autosomal-dominante Erbgang beobachtet. Mit einer Neumutationsrate von lediglich $10 \%$ ist in den meisten Fällen eine positive Familienanamnese zu eruieren (Wang et al. 2014). Damit ist die Analyse des Familienstammbaums ein wichtiger diagnostischer Schritt. 
Das XLAS beruht auf Mutationen, die das X-Chromosom betreffen. Auf diesem ist die $\alpha(5)$ Kette des Kollagens-IV auf dem Gen COL4A5 codiert. Insgesamt sind bei dem XLAS mittlerweile über 600 Mutationen beschrieben (Hertz et al. 2012). Als Mutationstypen sind die missense-, frameshift-, large rearrangements-, nonsense-, inframe- und splicemutationen beschrieben. Bei inframe-, missense- oder splicemutationen, also Mutationstypen, die zur Folge haben, dass die Kollagenketten lediglich einen Strukturschaden aufweisen, kommt es zu einer milderen Verlaufsform des AS. Bei den Patienten schreitet der Krankheitsverlauf langsamer voran, und eine Niereninsuffizienz tritt meist erst nach dem 30. Lebensjahr auf. Auch kommen Innenohr- und Augenveränderungen seltener vor (Gross 2002).

Mutationen, die dazu führen, dass die Kollagenketten nicht ausgebildet werden (frameshift, nonsense, large-rearrangement), gehen mit der juvenilen Form und damit progressiveren Formen des AS einher (Hudson et al. 2003).

Die häufigste Mutation ist eine missense-Glycin-Substitution. Dabei ist entscheidend, an welcher Stelle des Exons die Mutation angesiedelt ist. Je näher die zu kodierende alphaKette die Mutation Richtung N-terminales Ende aufweist, desto milder ist der Verlauf. Bei dem XLAS ist eine deutliche Phänotyp-Genotyp-Korrelation zu beobachten, die vor allem bei den männlichen Betroffenen stark ausgeprägt ist (Jais 2003).

Der autosomal-rezessive Typ des AS ist mit etwa 15\% sehr viel seltener (Flinter et al. 1988). Beim ARAS sind die auf dem Chromosom 2 lokalisierten Gene COL4A3 und COL4A4 betroffen. Dies führt $\mathrm{zu}$ fehlerhaften $\alpha 3$ - und $\alpha 4$-Ketten. Es kann ein homozygoter oder compound-heterozygoter Mutationsmechanismus zugrunde liegen (Oka et al. 2014). Weibliche wie auch männliche Patienten sind in diesem Fall in gleicher Weise betroffen. Oft findet sich bei den Betroffenen eine leere Familienanamnese. Liegt eine heterozygote Mutation vor, so führt dies zum Carrier-Status des ARAS.

\subsection{Klinisches Erscheinungsbild}

Das Alport-Syndrom präsentiert sich mit renalen und extrarenalen Symptomen. Die renalen Symptome zeigen sich in Form von Hämaturie und Proteinurie bis hin zur terminalen Niereninsuffizienz. Hinzu kommen extrarenale Symptome, welche sich an Ohr und Auge manifestieren. Die Ausprägung der Symptome hängt dabei von dem Vererbungsmuster ab. Charakteristisch ist eine Hämaturie, welche bei allen männlichen Alport-Trägern meistens schon in der frühen Kindheit auftritt. Weibliche sowie männliche Patienten mit dem rezessiven Typ des AS weisen ebenso eine (persistierende) Hämaturie auf. Carrier des AS zeigen typischerweise eine intermittierende Mikrohämaturie (Kashtan 1999). In einer Studie von Jais et al. (2003) wiesen über $95 \%$ der Carrier eine Mikrohämaturie auf. Das AS führt durch einen zunehmenden Funktionsverlust der GBM zur Proteinurie und Niereninsuffizienz. So ist das Auftreten einer Proteinurie in Abhängigkeit von der Schwere der Ausprägung der Erkrankung mit dem Alter der 
Patienten gekoppelt. Der fortschreitende Funktionsverlust der Niere zeigt sich bei den männlichen Patienten darin, dass mit dem Erreichen des 40. Lebensjahrs etwa $90 \%$ der Betroffenen eine terminale Niereninsuffizienz entwickelt haben. Ebenso sind beide Geschlechter mit ARAS von der Proteinurie betroffen. Auch die heterozygoten Mutationsträger tragen ein Risiko, eine Proteinurie zu entwickeln. Es sind Verläufe bis hin zur terminalen Niereninsuffizienz beschrieben (Jais 2003; Jais et al. 2000).

Die extrarenalen Veränderungen manifestieren sich am $\mathrm{Ohr}$ und am Auge. Eine Hochtonschwerhörigkeit konnte in 80\% der Träger nachgewiesen werden (Jais et al. 2000). Bei den Carriern weisen etwa ein Viertel der Patienten eine Hörminderung auf (Jais 2003). Dabei ist die Hörminderung nicht angeboren, entwickelt sich aber vielmehr im Laufe der Zeit und kann sich klinisch sehr variabel zeigen. Betroffen sind anfangs die HochtonFrequenzen zwischen 2000 und $8000 \mathrm{~Hz}$. Später können weitere Frequenzbereiche involviert sein. Es wird vermutet, dass der Ort des Defekts in der Cochlea sitzt. Dabei spielen eine Verdünnung einerseits sowie Verdickungen andererseits an verschiedenen Anteilen der Basalmembran eine Rolle (Kashtan 1999). Harvey et al. konnten zeigen, dass beim AS im Tiermodell das Ligamentum spirale Defekte in der Kollagenstruktur der $\alpha$ 3/4/5-Kollagenketten aufweist (Harvey et al. 2001). Ebenso konnte auch in der Stria vascularis eine Fehlregulierung von MMP beobachtet werden (Gratton et al. 2005). Die Studie von Jais et al. konnte aufweisen, dass Patienten mit einer Hochtonschwerhörigkeit ein erhöhtes Risiko haben eine terminale Niereninsuffizienz zu entwickeln (Jais et al. 2000). Folglich ist die frühzeitige Abklärung des Hörvermögens umso wichtiger für einen rechtzeitigen Therapiebeginn.

Die Augenbeteiligung beim AS weist ein breites Spektrum auf. Jedoch sind die Augenveränderungen nicht angeboren und einem Entwicklungsprozess unterlegen. Am häufigsten werden bei AS-Patienten perimakuläre Flecken als sogenannte dot-and-fleckRetinopathie beschrieben. Jedoch sind diese nicht spezifisch für das AS. Bei dieser Augenveränderung wird von einem Defekt der Bruch'schen Membran ausgegangen (Kashtan 1999; Fawzi et al. 2009). Ein weiteres Symptom ist der anteriore Lenticonus. Dieser gilt als pathognomonisch für das Alport-Syndrom. Etwa ein Viertel der Träger weist diese Augenveränderung auf (Choi et al. 2005). Der anteriore Lenticonus tritt vor allem bei der rasch progredienten Verlaufsform des AS auf.

Auch hier konnte gezeigt werden, dass bei Mitbeteiligung des Auges das Risiko erhöht ist, die terminale Niereninsuffizienz vor dem 30. Lebensjahr zu erreichen (Tan et al. 2009).

Eine Sonderform ist die klinische Assoziation des Alport-Syndroms zur Leiomyomatose. In diesem Fall tritt das AS zusammen mit der Leiomyomatose des Ösophagus, der Trachea und, bei weiblichen Patienten, des Genitaltraktes auf. Dabei sind die glatten Muskelzellen dieser Organe betroffen. Das gleichzeitige Vorkommen der Leiomyomatose ist selten und mit einem raschen Verlauf der Erkrankung assoziiert. Die Leiomymatose tritt 
auf wenn es durch eine große Deletion zu einem Verlust des 5'-Endes des COL4A5 und COL4A6, sowie der Promoterregion kommt. Die beiden Gene liegen Kopf an Kopf auf dem X-Chromosom (Zhang et al. 1996).

Das Syndrom der dünnen Basalmembran (kurz: TBMN) ist eine genetische Erkrankung, welche mit einer persistierenden Hämaturie einhergeht, selten jedoch mit einer Nierenfunktionseinschränkung. Schätzungsweise ist 1\% der Bevölkerung betroffen (Savige et al. 2003). Im Elektronenmikroskop zeigt sich eine charakteristisch verdünnte Basalmembran der Glomeruli. Wie bei dem AS liegt eine Störung der Kollagen (IV) Synthese aufgrund von Mutationen der COL4A3-/COL4A4-Gene vor. Mittlerweile sind auch hier über 20 Mutationen dieser Gene bekannt (Rana 2005). Entscheidend sind hier die heterozygoten Mutationen dieser Gene. Denn homozygote oder compound-heterozygote Mutationen würden zu einem Trägerstatus des ARAS führen (Tryggvason und Patrakka 2006). In einer Arbeit von Savige et al. konnte gezeigt werden, dass etwa $40 \%$ der diagnostisch geführten TBMN denselben Mutationsort aufweisen wie für das ARAS (Savige et al. 2003). Somit konnte bestätigt werden, dass die TBMN mit dem Status eines heterozygoten autosomal rezessiven Carriers einhergehen kann. Dabei ist die korrekte Diagnostik entscheidend, da die Gefahr besteht, den heterozygoten Carrierstatus des AS zu übersehen.

\section{Diagnostik:}

Die Diagnostik des AS stützt sich auf vier Säulen. Diese umfassen:

- die Familienanamnese mittels Stammbaumauswertung

- die klinische Präsentation des Patienten

- eine Nieren- (oder Hautbiopsie)

- eine Genanalyse

Der wichtigste Schritt ist die möglichst genaue Erfassung der Symptome. Die Diagnostik umfasst zum einen die Analyse der Nierenfunktion (Hämaturie, Proteinurie, KreaClearance) und zum anderen die Erfassung der extrarenalen Symptome (dot-and-fleckRetinopathie, Lenticonus anterior, Hochton-Schwerhörigkeit).

Die Stammbaumanalyse der Familie der betroffenen Patienten gibt weitere Aufschlüsse über die zugrundeliegenden Vererbungsmuster.

Eine Nierenbiopsie sollte bei unklaren Kriterien für das AS durchgeführt werden. Unter dem Lichtmikroskop zeigt sich am häufigsten eine fokal segmentale Glomerulosklerose. Dies ist jedoch ein unspezifischer Befund, welcher durch verschiedenste Mechanismen ausgelöst werden kann (Korbet 2002). Die Auswertung mittels Elektronenmikroskopie ist dabei die sicherste Art der Diagnostik (Kashtan et al. 2013). Wegweisende Befunde sind die Aufsplitterung und Verdickung der GBM. Die Podozyten wirken degeneriert und 
verschmolzen (Kruegel et al. 2013). Die Hautbiopsie kann bei XLAS sinnvoll sein, da auch in der Basalmembran der Haut $\alpha 5$-Ketten des Kollagen(IV) zu finden sind und diese Biopsie weniger invasiv ist als die Nierenbiopsie (Hertz 2009). Jedoch können bei COL4A5 missense-Mutationen dennoch Anteile exprimierter $\alpha 5$-Ketten in der Hautbiopsie gefunden werden. Auch bei Frauen und Mädchen kann die Aussagekraft der Hautbiopsie verfälscht sein, da es aufgrund der X-Inaktivierung zu einer Mosaikkonstellation von Zellen mit und ohne $\alpha 5$-Ketten kommen kann (Massella et al. 2003). Damit hat die Hautbiopsie einen geringeren Stellenwert als die Nierenbiopsie.

Mittlerweile ist es auch möglich, gezielt nach den Mutationen im Kollagen(IV)-Gen zu suchen. Auch wenn die genetische Untersuchung aufwendig ist, ist sie mit einer Sensitivität von etwa 95\% (Hertz et al. 2012) der Goldstandard der Diagnosestellung. Gerade bei jungen, noch oligo- oder nicht symptomatischen Patienten ist es entscheidend frühzeitig mit der Therapie zu beginnen. Die größten Chancen zur optimalen Therapie ergaben sich in einem Mausmodell bei einem Therapiebeginn in einem Stadium, bei dem es noch nicht zu einer Proteinurie gekommen war (Gross et al. 2003).

Aktuell erhält die Gendiagnostik zunehmend einen größeren Stellenwert. Zum einen besteht der Vorteil einer nicht-invasiven Diagnostik. Dies erlaubt vor allem bei Kindern eine risikoarme Diagnostik. Zum anderen sind durch sinkende Preise, eine mittlerweile fast flächendeckende Verfügbarkeit und fortgeschrittene Analyseverfahren die Einsatzmöglichkeiten der Gendiagnostik gestiegen.

\subsection{Therapie}

Die Therapie des AS stellt eine große Herausforderung dar, da bis heute die Nierentransplantation die einzige kausale Therapieoption darstellt. Mit dem zunehmenden Wissen um die Pathogenese des AS wurden verschiedene Therapiestrategien entwickelt. Anhand von Tiermodellen konnten wichtige Schritte bei der Etablierung von medikamentösen Behandlungsmöglichkeiten eruiert werden. Grundsätzlich beruht die Therapie des AS auf der Reduktion von Risikofaktoren, welche ein Fortschreiten des Funktionsverlustes und Sklerosierung der glomerulären Filtereinheit bewirken.

Der vielversprechendste Therapieansatz ist die Behandlung mit ACE-Hemmern (kurz: ACEi). ACEi sind jahrelang erprobte Substanzen, die neben der antihypertensiven Wirkung auch Einfluss auf die Proteinurie und Fibrosierung haben. Die Nebenwirkungen und Dosierungsstufen sind jahrelang erprobt (Kashtan et al. 2013). Mittlerweile konnte anhand von Registerauswertungen gezeigt werden, dass die Therapie mit ACEi erfolgsversprechend ist (Gross et al. 2012b). Vorausgegangen war ein erfolgreiches Experiment mit Alport-Mäusen, welche über die Nahrung einen ACEi über einen längeren Zeitraum zugefüttert bekamen. Die Ergebnisse zeigten eine deutliche Verlängerung der Überlebenszeit in Bezug auf das Erreichen der terminalen Niereninsuffizienz (Gross et al. 
2003). Diese Ergebnisse gelten als Grundlage für die Therapieoption mit ACEi auch beim Menschen.

Allerdings handelt es sich bei der Therapie nach wie vor um eine off-label-Therapie, welche zusätzlich durch die Tatsache erschwert wird, dass das Alport-Syndrom bereits Kinder betrifft. Die meisten ACEi, vor allem Ramipril, das nur einmal täglich genommen werden muss, sind für Kinder nicht zugelassen. Dennoch gelten ACEi auch bei Kindern als Mittel der Wahl zur Behandlung eines Bluthochdrucks. Typische Nebenwirkungen wie Reizhusten, Hyperkaliämie, allergische Hautreaktionen, Kopfschmerzen, Übelkeit und Durchfall werden selten beobachtet. Um eine Therapie bei Kindern zu etablieren, wurde eine randomisierte Placebo-kontrollierte Studie ins Leben gerufen (EARLY PRO-TECT), die sich momentan in der Behandlungsphase befindet (Gross et al. 2012a).

\section{Das Renin-Angiotensin-Aldosteron-System (kurz: RAAS) und Wirkung der ACE- Hemmer}

Das RAAS ist ein wichtiger Regelkreislauf, um den Wasser- und Salzhaushalt des Körpers aufrechtzuerhalten und somit auch eine wichtige Komponente der Blutdruckregulation. Das System besteht aus folgenden Komponenten:

Renin: Protease, die im juxtaglomerulären Apparat der Niere gebildet und bei Salz-und Druckabfällen sezerniert wird.

Angiotensin: Angiotensin I, das durch Renin aus dem aus der Leber stammenden Angiotensinogen abgespalten wird. Angiotensin I wird durch weitere Spaltung durch das Angiotensin-Converting Enzym (ACE) in Angiotensin II umgewandelt. Dieses hat nun effektorische Auswirkung auf die Vasokonstriktion der kleinen Blutgefäße, die Sekretion des antidiuretischen Hormons (kurz ADH), die Konstriktion der Vas efferentia des glomerulären Apparates und vor allem auf die Freisetzung des Mineralocorticoids Aldosteron.

Aldosteron wird in der Nebennierenrinde produziert und über die Wirkung von Angiotensin II an den AT1-Rezeptoren sezerniert. Aldosteron bewirkt über einen vermehrten Einbau von epitheliaren Natriumkanälen (kurz: eNaC) in die Sammelrohre des glomerulären Apparates einen erhöhten Natriumtransport über das Endothel in das Interstitium und somit eine gesteigerte Wasserrückresorption aus den Tubuli der Sammelrohre. Gleichzeitig findet kompensatorisch ein erhöhter Transport von Kalium und Protonen in die Tubuli statt (Remuzzi et al. 2005).

Neben diesem klassischen Modell des Regelkreislaufs ist auch die profibrotische und inflammatorische Komponente des RAAS zu beachten. Im Zusammenhang mit der diabetischen Nephropathie ist heutzutage bekannt, dass Angiotensin II über eine Stimulation von TGF $\beta$ und anderen Mediatoren wie Chemokinen, Cytokinen und NFKB eine proinflammatorische Wirkung ausübt (Siragy und Carey 2010). Oxidativer und 
mechanischer Stress scheinen diesen Prozess auf das Glomerulum zu verstärken. Es kommt zur Anreicherung von extrazellulärer Matrix und fibrotischen Umbauprozessen.

Mit der medikamentösen Hemmung des RAAS kann bei der diabetischen Nephropathie eine Verlangsamung des Prozesses beobachtet werden (Gilbert et al. 2003). In Übertragung auf die pathogenetischen Prozesse, die auch beim Alport-Syndrom zu einer chronischen Niereninsuffizienz führen, ist die RAAS-Blockade mittels ACEi bzw. AT1Rezeptorantagonisten eine wesentliche Therapiestrategie.

ACE-Hemmer verringern die Proteinurie und führen durch das Herunterregulieren von TGFß1 zu einer geringeren Fibrosierung der GBM und einer geringeren Akkumulation von extrazellulärer Matrix (Gross et al. 2003; Webb et al. 2011; Gross et al. 2012b). Gross et al. konnten in einem COL4A3-knockout-Mausmodell zeigen, dass eine Gabe von Ramipril vor Auftreten einer Proteinurie zu einer Verzögerung des Nierenversagens führte (Gross et al. 2003). In einer Registerauswertung konnten Gross et al. zeigen, dass auch bei Alport-Patienten die Therapie mit ACEi eine Verzögerung des Nierenversagens bewirkt (Gross et al. 2012b). Die Therapie muss unter steter Kontrolle erfolgen. Nebenwirkungen sind selten beobachtet, aber für die Therapieentscheidung bedeutsam (Gross et al. 2012b). Der größte Effekt wurde bei früher Gabe, also noch vor Auftreten der Proteinurie, beobachtet. Die Therapie erfolgt vor allem mit Ramipril (0.025-0.1 $\mathrm{mg} \mathrm{kg}^{-1}$ Körpergewicht) und Enalapril (0.125-1.0 mg kg-1 Körpergewicht). Der Übergang von einer Mikroalbuminurie auf die Proteinurie scheint entscheidend für die Effektivität der ACEHemmer zu sein. Allerdings stellt sich die Frage, ob bereits im frühen Stadium der Mikrohämaturie oder Mikroalbuminurie mit einer Intervention mit ACEi begonnen werden soll (Gross et al. 2012b). Das setzt eine frühzeitige und gesicherte Diagnose voraus. In einem Konsenspapier von führenden Alport-Forschern wird eine Empfehlung sowohl für ACEi als Erstlinientherapie als auch zum Therapiebeginn vor dem Auftreten einer Proteinurie abgegeben (Savige et al. 2013; Kashtan et al. 2013).

Losartan und Candesartan als AT1-Blocker kommen vor allem bei Nebenwirkungen der ACEi zum Einsatz. Ein Vorteil aus einer zusätzlichen Therapie mit ACEi konnte bislang nicht gezeigt werden.

Aldosteroninhibitoren gelten momentan neben den Angiotensin-Rezeptor-Blockern (kurz: ARB) als Zweitlinientherapie nach den ACEi (Kashtan et al. 2013). Auch diese Substanzklasse scheint neben dem blutdrucksenkenden Einfluss auch Auswirkungen auf die Proteinurie zu haben. Auch die Kombination von ACEi mit Aldosteroninhibitoren wie Spironolakton scheint eine weitere Reduzierung der Proteinurie zu bewirken (Giani et al. 2013; Kaito et al. 2006).

Auf ähnliche Weise können HMG-CoA-Reduktase-Hemmer die Ablagerungen der extrazellulären Matrix und die Expression von TGF verringern. Der Effekt ist allerdings im Vergleich zu den ACEi schwächer ausgeprägt (Koepke et al. 2007). Die Frage nach einer Kombinationstherapie und deren Vorteil mit ACEi oder ARBs steht noch offen. 
Die Nierentransplantation stellt die einzige kurative Behandlung dar. Es bestehen grundsätzlich die Möglichkeiten der Leichen- oder Lebendspende. Bei der Lebendspende muss im Falle der Mutter als Spenderin ein möglicher Carrierstatus bestimmt werden, da heterozygote Carrier nicht uneingeschränkt als Primärspender in Betracht kommen sollten. Hier ist eine gründliche Abwägung der klinischen Symptome und der bestehenden Risiken nötig (Gross et al. 2009b). Ein Transplantatversagen aufgrund von Anti-GBM-Antikörpern und RPGN wird in ca. 5\% der Fälle beobachtet. Betroffen sind hierbei vor allem Patienten mit der juvenilen Form des AS (Kashtan 2006).

Weitere experimentelle medikamentöse Therapieansätze beruhen auf eine Reduktion des inflammatorischen Prozesses. Dabei spielen Komplement-Inhibitoren, MMP Inhibitoren (Zeisberg et al. 2006), Chemokin-Rezeptor-Antagonisten, Vasopeptidase-Inhibitoren (Gross et al. 2005), Bone-Morphogenetic Protein Hemmer (Zeisberg et al. 2003), TGF- $\beta$ Blocker (Sayers et al. 1999) und auch die Stammzelltransplantation (Gross et al. 2009a) wichtige Rollen. Bisher beruhen die wissenschaftlichen Erkenntnisse nur auf Experimenten mit Tiermodellen und finden bislang keine Anwendung beim Menschen. 


\section{Methoden}

Das dieser Arbeit zugrunde liegende Alport-Register wurde von Prof. Gross im Jahr 2006 ins Leben gerufen. Der größte Anteil der erfassten Patientendaten kommt aus Deutschland, des Weiteren sind Patientendaten aus Spanien, Frankreich, Belgien, Österreich und der Schweiz erfasst. Für die Auswertung im Rahmen der vorliegenden Arbeit wurden nur Patienten aus deutschen Zentren (bundesweit vierzehn Zentren) eingeschlossen. Die Grundlage der Verlaufsdaten bildeten zum einen Follow-up-Daten der schon bestehenden Datensätze im Zeitraum 2011 bis 2014. Weiterhin konnten wir 17 neue Patienten in das aktuelle Register einschließen. Alle Patienten hatten ihr schriftliches Einverständnis gegeben. Für die Datenabfrage wurde ein Fragebogen entwickelt, der über den Postweg und via E-Mail-Kontakt an die Patienten persönlich beziehungsweise an die bundesweiten Zentren versendet wurde. Darüber hinaus wurden über die AlportSprechstunde an der Universität Göttingen (Prof. O. Gross) neue Daten erhoben und in das Register eingepflegt. Zur Datenauswertung wurden nur Patienten eingeschlossen, bei denen das Alport-Syndrom sicher diagnostiziert ist. Dafür musste eine molekulardiagnostisch beziehungsweise histologisch gesicherte Mutation im COL4A5 oder COL4A3/4 vorliegen. Dabei war entscheidend, ob die typische Befundkonstellation im Elektronenmikroskop oder eine genetische Testung beziehungsweise eine klassische Klinik mit Hämaturie, Proteinurie, Niereninsuffizienz plus extrarenalen Manifestationen vorlag.

Die Alport-Datenbank umfasst folgende Informationen:

\section{- Allgemeine epidemiologische Patientendaten:}

Zentrum, Alter, Geschlecht, Familienzugehörigkeit, Größe, Gewicht, Carrier- oder Trägerstatus

- Risikofaktoren:

Hypertonie, Rauchen

- Diagnosekriterien:

Mutationsanalyse, Biopsieergebnisse, extrarenale Veränderungen

- Aktuelles Krankheitsstadium:

Gesamtprotein im Urin, Kreatinin-Clearance, Dialyse, Transplantation, Tod

- Einteilung in klinische Stadien:

Stadium 0-5 (siehe unten)

- Therapie:

ACE-Hemmer, AT1-Blocker, CSE-Hemmer, Therapiebeginn, Nebenwirkungen

- Informationen über Erstmanifestation und Dauer bis zur Diagnosestellung 
Alle Patientendaten wurden anonym gespeichert und ausgewertet. Dabei erhielt jeder Patient eine Zeichenkombination aus Buchstabe und Ziffer (Pseudonymisierung). Die zentrale Datenbank ist auf einem nicht öffentlichen Rechner an der Universität Göttingen im Zuständigkeitsbereich von Herrn Prof. O. Gross hinterlegt. Es erfolgte zudem eine Verschwiegenheitserklärung der involvierten Mitarbeiter.

Die Datenerfassung im Rahmen des Alport-Registers erfolgte auf Grundlage des positiven Ethikentscheides AZ 10/11/06. Die Datenaufnahme erfolgte freiwillig und es ergaben sich keine Nachteile in Bezug auf Therapieoptionen gegenüber den Patienten. Die Auswertung des Registers beruht auf einer prospektiven Verlaufsbeobachtung. Alle Patientenformationen sind anonymisiert erfasst und ausgewertet worden.

Das dieser Arbeit zugrundeliegende Datenkollektiv beläuft sich auf 65 Patienten, bei denen ein vollständiger Datensatz erhoben werden konnte. Für die prospektive Verlaufsstudie wurden 56 Patienten eingeschlossen. Für diese lagen vollständige Datensätze sowohl für den Zeitpunkt 2011 als auch für 2014 vor.

Es ergeben sich somit zwei Schwerpunkte bei der statistischen Auswertung. Zum einen erfolgte eine deskriptive Auswertung der erhobenen Items des Gesamtkollektivs ( $n=65$ ). Zum anderen wurde im Rahmen der Verlaufsbeobachtung der prospektive Verlauf der 56 Patienten ausgewertet. Hierbei war der Therapieerfolg mittels RAAS-Blockade in Bezug auf das Fortschreiten des Krankheitsstadiums von besonderem Interesse. Als Kontrollgruppe galt die Kohorte Patienten, welche keine Therapie erhalten hat. Als Grundlage wurden im Alport-Register folgende Krankheitsstadien definiert:

- Stadium 0: Hämaturie (>4 Erythrozyten/Gesichtsfeld bei 400x Vergrößerung)

- Stadium 1: Mikroalbuminurie (bis $300 \mathrm{mg} / \mathrm{d}$ )

- Stadium 2: Proteinurie (größer $300 \mathrm{mg} / \mathrm{d}$ )

- Stadium 3: eingeschränkte Nierenleistung (GFR kleiner $60 \mathrm{ml} / \mathrm{min}$ )

- Stadium 4: Terminale Niereninsuffizienz / Nierenersatzverfahren (Dialyse, Transplantation)

- Stadium 5: Verstorben

Im Zuge der Verlaufsbeobachtung wurde eine Endpunktanalyse durchgeführt. Dabei diente das Alter bei Eintritt in das Nierenersatzverfahren als definierter Endpunkt.

Im Zuge der Verlaufsbeobachtung kam es bei Endpunktanalyse zu zensierten Daten, wenn in dem genannten Beobachtungszeitraum (2011 bis 2014) die Patienten den Endpunkt noch nicht erreicht haben bzw. schon verstorben waren. Die medianen Überlebenszeiten wurden mit dem Kaplan-Meier-Schätzer grafisch dargestellt und mittels log-rank-Tests validiert. Bei der Auswertung der Therapie wurde der Beginn der medikamentösen Therapie in drei Stadien unterteilt. Dieser Einteilung zugrunde liegen die klinischen Stadien des AS:

- ACE I: Im Stadium der Mikroalbuminurie begonnene Therapie 
- ACE II: Im Stadium der Proteinurie begonnene Therapie

- ACE III: Im Stadium mit einer GFR $<\mathbf{6 0} \mathbf{~ m l} / \mathbf{m i n}$ begonnene Therapie

Die bei der statistischen Auswertung angegebenen Mediane und Spannweiten geben stets das 95\%-Konfidenzintervall an. Alle genannten p-Werte sind zweiseitig getestet und statistisch signifikant bei Werten unter $\mathrm{p}=0,05$.

Die statistische Auswertung erfolgte mit Microsoft Excel Professional Plus 2010 Version 14.0 (Microsoft Corporation), STATISTICA Version 12.5 (StatSoft Europe GmbH) und R Version 3.1.2 (R Core Team). Die statistische Beratung erfolgte durch das Institut für Medizinische Statistik Göttingen. 


\section{Ergebnisse}

\subsection{Das Alport-Register}

Das Register beinhaltet ca. 400 Patienten, von denen 161 Patienten aktualisiert werden konnten. Diese Arbeit wertet den Anteil an heterozygoten Mutationsträgern (Carrier) aus. Dieser beläuft sich auf 65 Patienten.

Die ausgewerteten Daten umfassen 58 weibliche Patienten mit einem Durchschnittsalter von 38,5 Jahren (bei $\mathrm{n}=55$, da bei drei Patientinnen keine Altersangabe vorhanden war) und sieben männliche Patienten mit einem Durchschnittsalter von 43,4 Jahren.

Tabelle 2: Aufteilung der Patienten auf die bundesweiten 14 Standorte

\begin{tabular}{|l|l|r|}
\hline Zentrum & Ort & $\mathbf{n}=\mathbf{6 5}$ \\
\hline Zentrum1 & Heidelberg & 1 \\
\hline Zentrum2 & Köln & 11 \\
\hline Zentrum3 & UMG Göttingen & 19 \\
\hline Zentrum7 & München & 1 \\
\hline Zentrum10 & Köln & 1 \\
\hline Zentrum14 & Leipzig & 3 \\
\hline Zentrum17 & MHH & 4 \\
\hline Zentrum20 & Wuppertal & 1 \\
\hline Zentrum26 & Recklinghausen & 1 \\
\hline Zentrum27 & Wiesbaden & 1 \\
\hline Zentrum29 & Nettetal, Dialyse & 1 \\
\hline Zentrum32 & Emden & 2 \\
\hline Zentrum34 & Horrem & 1 \\
\hline Sonstige & Sonstige & 18 \\
\hline
\end{tabular}

Für die Verlaufsbeobachtung wurden die Stichjahre 2011 und 2014 gewählt. Der Zeitraum wurde vom 01.01.2011 bis 31.12.2014 eingegrenzt. Für 52 Patienten lagen komplette Datensätze für beide Jahre vor. Nur diese sind in die Vergleichs- und Verlaufsbeobachtung eingeflossen. Es ergab sich für die 52 Datensätze eine mittlere Verlaufsbeobachtungszeit von $46 \pm 10$ Monate. Da 2011 die Mehrzahl der Patienten schon unter Therapie standen, 
ergibt sich eine mittlere Therapiedauer von 8,4 $\pm 4,4$ Jahren (Spannweite: 2-18 Jahre, Median: 7).

Für die deskriptive Auswertung des Registers wurden alle vollständigen Datensätze 2014 eingeschlossen ( $\mathrm{n}=65)$ - also auch die Patienten, die zwischenzeitlich neu in das Register aufgenommen wurden und demnach nur einen Datensatz zum Stichjahr 2014 aufwiesen.

\subsubsection{Auswertung des aktualisierten Alport-Registers}

Das mittlere Alter von den 65 ausgewerteten Patienten liegt bei 39,13 Jahren. Die Werte liegen zwischen 6 und 81 Jahren bei einem Median von 38,5 Jahren. In dem Datensatz befinden sich 58 Patientinnen und 7 Patienten (mittleres Alter: 43,43).

Bei 76,2 \% (48/63) der Patienten liegt ein X-chromosomaler Erbgang vor. Dagegen liegt bei 23,8 \% (15/63) der Patienten eine autosomal rezessive Erbfolge vor. In dieser Gruppe befinden sich auch alle männlichen Patienten.

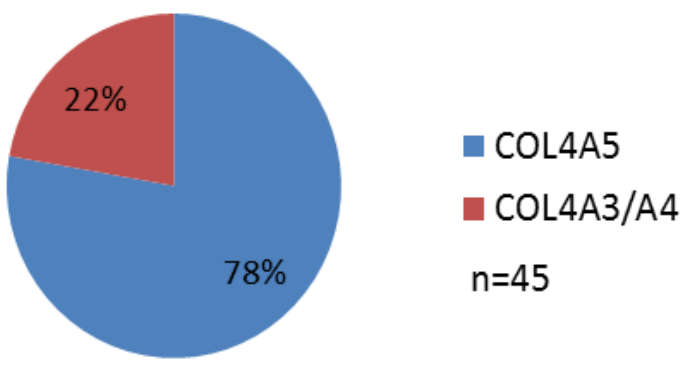

Abbildung 1: Verteilung der Erbgänge

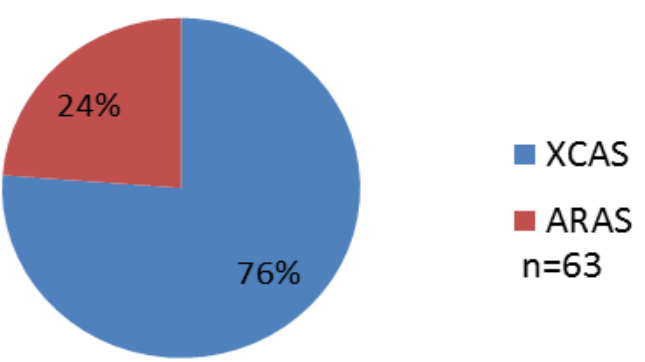

Abbildung 2: Verteilung der Mutationen 
In der folgenden Abbildung ist der Kaplan-Meier-Schätzer für die beiden Erbgänge in Bezug auf das Erreichen des Endpunktes Dialyse (auch: renal replacement therapy, kurz: RRT) dargestellt. Im Vergleich stehen hier 47 Patienten mit X-chromosomalen und 16 Patienten mit autosomal-rezessiv vererbtem AS. Mit dem Alter von 60 Jahren haben 16\% der Patienten mit XLAS und 37\% der Patienten mit ARAS den Endpunkt RRT erreicht. Bei 71,43 \% (45/63) aller Fälle konnten Mutationen im COL4-Gen nachgewiesen werden. Mit $77,77 \%(\mathrm{n}=35)$ überwiegt die Mutation im COL4A5, die mit dem XLAS assoziiert ist.

Bei der Unterscheidung der Mutationsarten konnten 23 Datensätze ausgewertet werden. Es dominiert die In-Frame-Mutation mit 73,91 \% der Fälle (17/23). Bei 26,09 \% liegt eine Deletion vor (6/23).

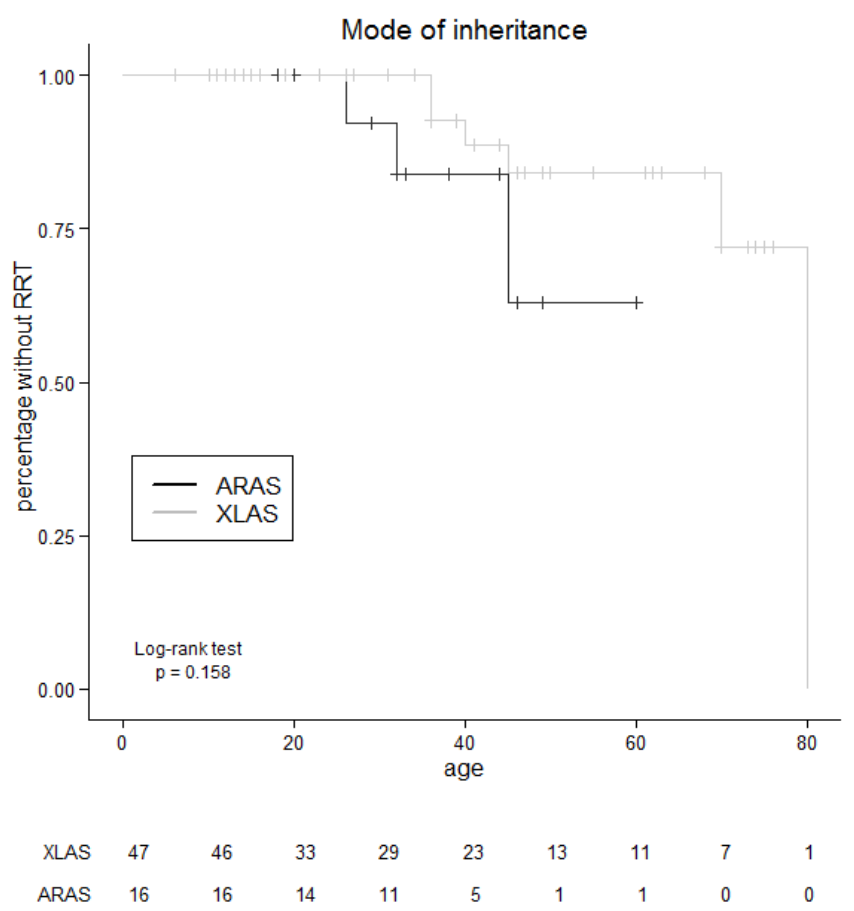

Abbildung 3: Vergleich der Vererbungsmuster in Bezug auf den Endpunkt RRT

\subsubsection{Nierenbiopsie}

Das Register erfasst die lichtmikroskopischen Befunde. Ein lichtmikroskopischer Befund liegt bei 11/65 der heterozygoten Mutationsträger vor. Die entspricht 7,2\% der gesamten Kohorte. Dabei überwiegt mit 45,45\% (5/11) die FSGS. Einmal lag eine nicht weiter klassifizierte glomeruläre Nephropathie vor. Fünf Proben wiesen keinen pathologischen Befund auf. Alle Patienten mit einer nachgewiesenen FSGS weisen eine Proteinurie auf, wobei über die Hälfte der Patienten (60\%) zusätzlich eine cochleäre Beteiligung hat. 


\subsubsection{Klinisches Erscheinungsbild und Therapie}

63,1\% (41/65) der Patienten stehen unter Therapie mittels RAAS-Blockade. Darunter stehen 38 Patienten unter einer ACEi-Therapie. Drei Patienten bekommen isoliert einen AT1-Antagonisten. Naheliegend ist hier, dass aufgrund von Nebenwirkungen der ACEiTherapie auf einen AT1-Antagonisten gewechselt wurde. Sechs Patienten erhalten eine Kombinationstherapie aus ACE-Hemmer und AT1-Blocker. Vier Patienten erhalten zusätzlich ein Statin. 24 Patienten (37,9\%) sind zum Stichpunkt 2014 nicht therapiert. Darunter befindet sich die Mehrheit der männlichen Patienten 57,1\% (4/7), die zudem alle den autosomal-rezessiven Alport-Typ aufweisen. Dabei liegt das Durchschnittsalter dieser Gruppe bei 42,85 Jahren (Median 41, Min/Max: 6/81). Im Vergleich dazu beträgt das Durchschnittsalter der Therapiegruppe 37,21 Jahre (Median 37, Min/Max; 10/76). Interessanterweise wurden alle Patienten, die den Endpunkt terminales Nierenversagen/Nierenersatzverfahren erreicht haben, nicht therapiert.

Das durchschnittliche Alter bei Beginn einer RAAS-Blockade betrug 29,87 Jahre bei einer Spannweite von vier bis 62 Jahren und einem Median von 32 Jahren. Der Beginn der Therapie mit einem ACEi wird anhand der vorliegenden Klinik des AS eingeteilt. Die einzelnen Dosierungen der ACEi sind nicht bekannt. Wurde die Therapie bei dem Vorliegen einer Mikroalbuminurie begonnen, ist dies als ACE I verschlüsselt. ACE II bedeutet ein Therapiebeginn bei dem Vorliegen einer Proteinurie. Ein späterer Therapiebeginn bei einer eingeschränkten GFR $<60 \mathrm{ml} / \mathrm{min}$ umfasst den Ausdruck ACE III. Bei 66,7\% (26/39) der Patienten wurde die ACEi-Therapie im Stadium der Proteinurie begonnen (ACEII). Rund ein Viertel der Patienten (11/39) hat mit dem Befund der Mikroalbuminurie (ACEI) die ACEi-Therapie begonnen. Lediglich 5,1\% (2/39) der Patienten hat erst im fortgeschrittenen Stadium (ACEIII) eine Therapie begonnen.

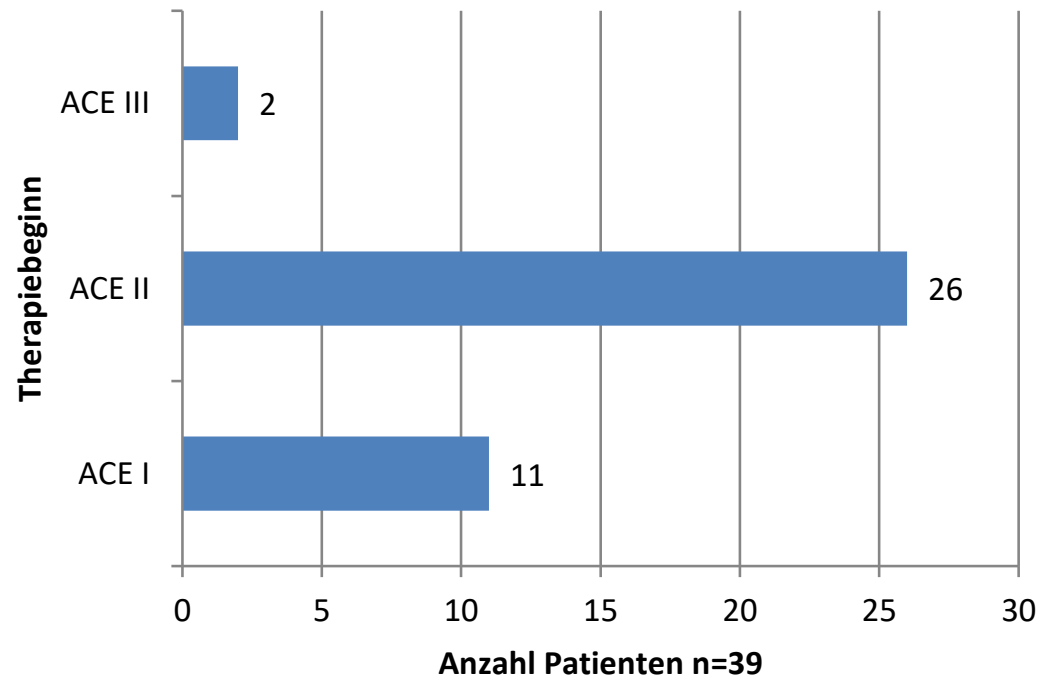

Abbildung 4: Patientenverteilung bezogen auf den Therapiebeginn 
Bei der Auswertung der Stadienverteilung zeigt sich, dass sich über zwei Drittel der Patienten in den Stadien 0 bis 2 befinden, wobei mit 41,5 \% das Stadium 2 am häufigsten vertreten ist.

Tabelle 3: Übersicht über die Therapiehäufigkeit

\begin{tabular}{|l|l|l|l|l|l|}
\hline \multirow{2}{*}{ Stadium } & \multirow{2}{*}{ Fallzahl } & \multirow{2}{*}{$\begin{array}{l}\text { Durchschnittsalter } \\
\text { (Jahre) }\end{array}$} & \multirow{2}{*}{$\begin{array}{l}\text { ACEi-Therapie } \\
\mathbf{( \% )}\end{array}$} & \multicolumn{2}{|c|}{ Therapiebeginn (\%) } \\
\cline { 5 - 6 } & & 20,2 & 33,3 & ACE I & ACE II \\
\hline \hline 0 & 6 & 36,6 & 50,0 & 50,0 & 50,0 \\
\hline 1 & 14 & 32,5 & 85,2 & 42,9 & 57,1 \\
\hline 2 & 27 & 58,7 & 77,7 & 30,7 & 69,3 \\
\hline 3 & 9 & 51,0 & 0,0 & 71,4 & 28,6 \\
\hline 4 & 7 & 75,5 & 0,0 & - & - \\
\hline 5 & 2 & & - & - \\
\hline
\end{tabular}

Im Stadium 4 befinden sich zum ersten Stichpunkt (2014) sieben Patienten mit einem Durchschnittsalter von 51 Jahren. Keiner der Patienten wird therapiert. Im Mittel wurde der Endpunkt RRT mit 42,12 Jahren (Median 36, Min/Max: 26/80) erreicht. 13,85\% (9/65) des untersuchten Kollektivs haben den Endpunkt Dialyse erreicht. Diese Patienten hatten bereits zum Stichjahr 2011 das Stadium 4 erreicht. Während des aktuellen Beobachtungszeitraumes hat sich kein Patient klinisch in das Stadium 4 verschlechtert.

Vier Patienten erhielten eine Nieren-Transplantation. Das mittlere Transplantat-Überleben beträgt 15,3 Jahre ( $\mathrm{n}=3)$.

Zwei der neun Patienten mit dem erreichten Endpunkt (22,2\%) sind verstorben (Stadium 5). Diese hatten zuvor bereits das dialysepflichtige Stadium erreicht. Eine Patientin war nierentransplantiert. Die genaue Todesursache ist nicht bekannt.

In den klinisch fortgeschrittenen Stadien, bei denen es bereits $\mathrm{zu}$ einer Funktionseinschränkung der Niere gekommen ist, stehen überdurchschnittlich viele Patienten unter ACEi-Therapie. Dem gegenüber stehen die Stadien mit nur geringer klinischer Symptomatik mit maximal 50\% der therapierten Patienten (Stadium 1). Von den Patienten mit isolierter Hämaturie steht ein Drittel unter Therapie. 


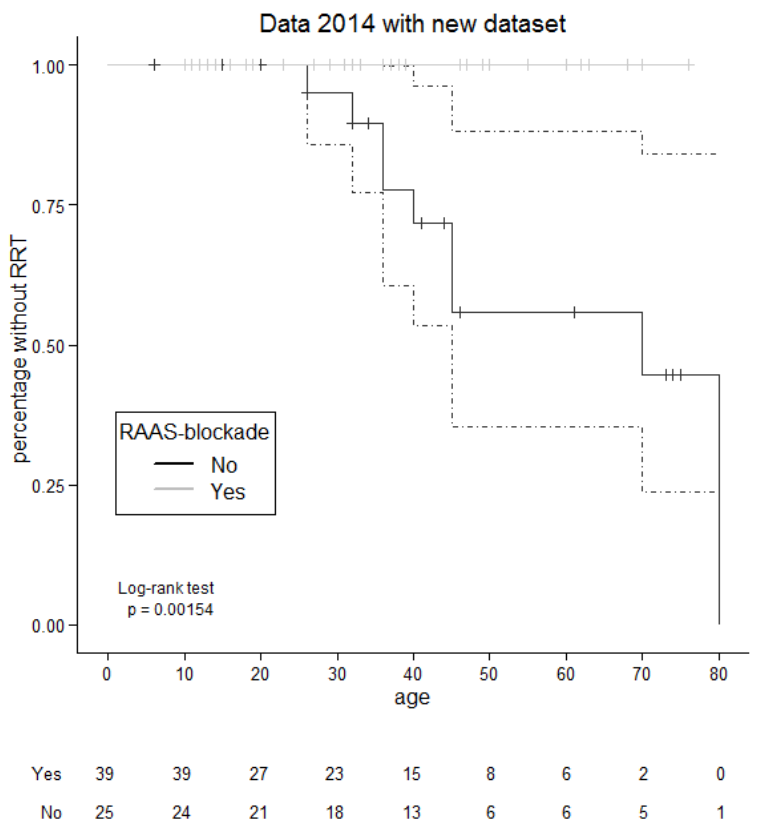

Abbildung 5: Kaplan-Meier-Schätzer der unter ACEi-Therapie stehenden Patienten

\subsubsection{Symptome bei Erkrankungsbeginn und Dauer bis zur Diagnosestellung}

Mit $18 \%$ ist die Mikrohämaturie das häufigste erste Symptom. Obwohl dieser Befund nur durch gezielte Testung aufgewiesen werden kann, tritt er am häufigsten auf. Dies beruht wahrscheinlich auf den Vererbungscharakter des AS und der Empfehlung, dass bei bereits betroffenen Familienmitgliedern ein Screening der verwandten Personen durchgeführt werden sollte. Ein Urinstix ist eine kostengünstige und schnelle Diagnostikhilfe bei Routineunteruchungen beim Hausarzt oder betrieblichen Vorsorgeuntersuchungen. Die Proteinurie als zweithäufigster Wert betrifft die Personen, bei denen das AS lange unerkannt blieb und zum Zeitpunkt der Diagnose schon fortgeschritten war.

Ein weiterer kleiner Datensatz mit 18 Patienten erfasst die Dauer vom ersten Symptom bis zur Diagnosestellung. Im Mittel dauerte es 8,1 Jahre bis zur Diagnosestellung. Die Patienten mit einer Mikrohämaturie als erstem Symptom hatten im Mittel nach 3,9 Jahren die Diagnose AS. Die Patienten mit einer Proteinurie als primärem Symptom wurden im Mittel erst nach 8,5 Jahren diagnostiziert. Die kleine Anzahl an Patienten erlaubt jedoch keine statistische Testung der Ergebnisse. 
Tabelle 4: Gegenüberstellung der ersten Symptome

\begin{tabular}{|c|c|c|c|}
\hline Erstes Symptom & Mikrohämaturie & Makrohämaturie & Proteinurie \\
\hline Fallzahl & $\mathrm{n}=12$ & $\mathrm{n}=2$ & $\mathrm{n}=7$ \\
\hline Stadium & $\begin{array}{l}\bar{x}=1,25 \\
\text { Min/Max:0;2 } \\
\text { Median:1,5 }\end{array}$ & $\begin{array}{l}\bar{x}=2,5 \\
\text { Min/Max:2;3 } \\
\text { Median:2,5 }\end{array}$ & $\begin{array}{l}\bar{x}=1,85 \\
\text { Min/Max:0;4 } \\
\text { Median:2,0 }\end{array}$ \\
\hline Dialyse & 0 & 0 & $14 \%$ \\
\hline Therapie (ACEi) & $58 \%$ & $100 \%$ & $43 \%$ \\
\hline Alter & $\begin{array}{l}\bar{x}=26,08 \\
\text { Min/Max:6;50 } \\
\text { Median:25 }\end{array}$ & $\begin{array}{l}\bar{x}=19,5 \\
\text { Min/Max:16;23 } \\
\text { Median:19,5 }\end{array}$ & $\begin{array}{l}\bar{x}=43,6 \\
\text { Min/Max:10;73 } \\
\text { Median:49 }\end{array}$ \\
\hline XLAS & $83 \%$ & $100 \%$ & $71 \%$ \\
\hline ARAS & $17 \%$ & 0 & $29 \%$ \\
\hline $\begin{array}{l}\text { Diagnosedauer } \\
\text { (Monate) }\end{array}$ & $\begin{array}{l}\bar{x}=42,3 \\
\text { Min/Max:0;180 } \\
\text { Median:12 }\end{array}$ & $\begin{array}{l}\bar{x}=2 \\
\text { Min/Max:2 }\end{array}$ & $\begin{array}{l}\bar{x}=102 \\
\text { Min/Max:12;360 } \\
\text { Median:18 }\end{array}$ \\
\hline
\end{tabular}

\subsubsection{Extrarenale Manifestationen}

Bei der aktuellen Registerauswertung wurden auch Daten zu den extrarenalen Manifestationen des Alport-Syndroms erfasst. Dabei konnten 29 Datensätze zur cochlearen Beteiligung ausgewertet werden. Von den 29 Patienten hatten 12 (41,38\%) einen positiven Befund, wobei eine exakte Unterscheidung der Schwerhörigkeit nicht erfolgte. Diese Patienten waren im Schnitt mit 47,12 Jahren 13 Jahre älter als die Gruppe mit unauffälligem Hörbefund (34,3 Jahre). Unter den 29 Patienten befanden sich drei dialysepflichtige Patienten. Diese finden sich geschlossen in der Gruppe mit positivem Hörbefund wieder. Somit erreichen 25 \% (3/12) der Patienten mit einer Hörminderung den Endpunkt RRT ( $\mathrm{p}=0,046$ im Mann-Whitney-U-Test, 95\% CI: 5\%-57\% mit exact binominal test). Lediglich die Hälfte dieser Kohorte ist therapiert (6/12), ein Drittel dieser Patienten erst bei einer schon fortgeschrittenen Erkrankung (ACE III).

Die Kohorte mit negativem Hörbefund ist nicht nur jünger, sondern auch mit $76,5 \%$ $(13 / 17)$ deutlich häufiger therapiert. Der Therapiebeginn dieser Patienten erfolgte in den frühen Stadien der Erkrankung (ACE I-II). 


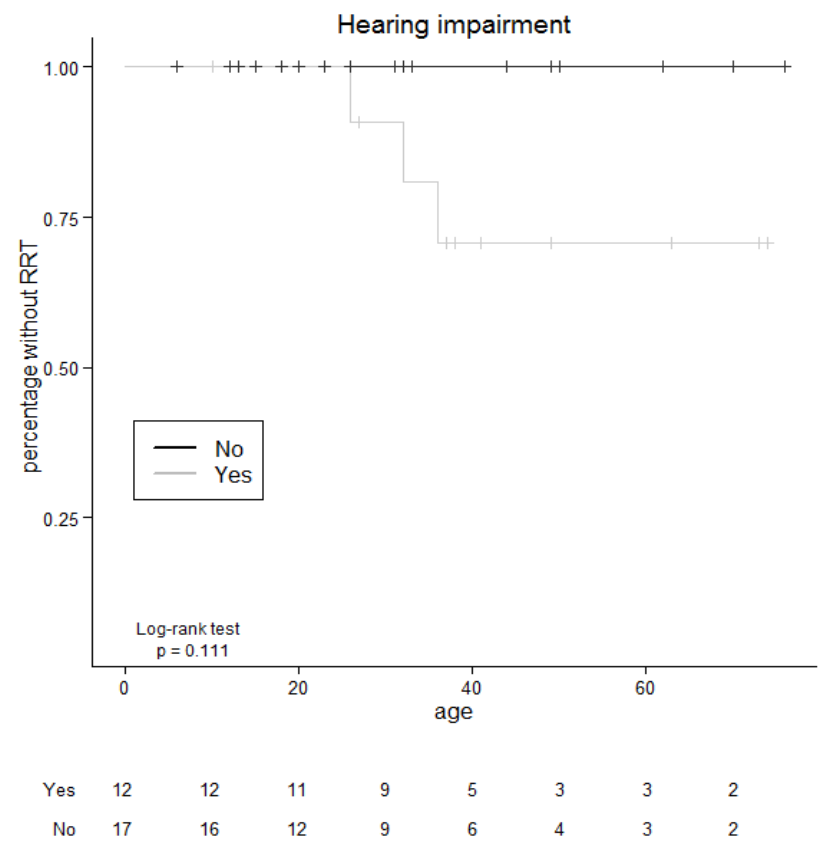

Abbildung 6: Kaplan-Meier-Schätzer der Patienten mit Schwerhörigkeit

24 Datensätze konnten zur okularen Beteiligung erfasst werden. Jedoch hatten nur 2 Patienten einen positiven Befund. Das Register erfasst lediglich pathologische Augenveränderungen ohne nähere Differenzierung. Somit erlaubt diese zu kleine Kohorte keine aussagekräftige Auswertung. Das Alter der beiden Patienten beträgt im Mittel 52 Jahre. Die Vergleichskohorte ohne Augenbeteiligung weist ein Durchschnittsalter von 38,5 Jahren auf.

Bei der Auswertung zeigte sich, dass bei $15 \%$ der Patienten bisher keine Höruntersuchung und bei $20 \%$ der Patienten bisher keine Abklärung einer Augenbeteiligung erfolgt ist.

Folgende Diagramme zeigen die Ergebnisse der Datensätze mit den Informationen über die Höruntersuchungen und Augenuntersuchung für.

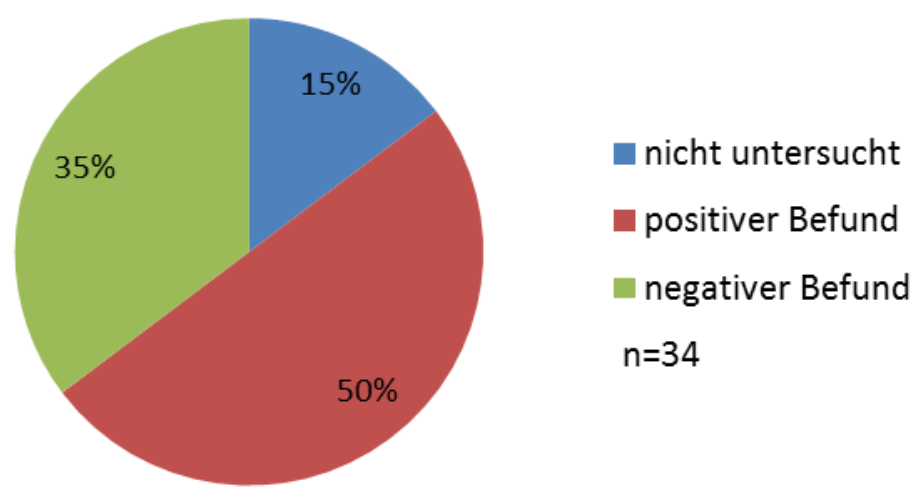

Abbildung 7: Ergebnis der Höruntersuchungen 


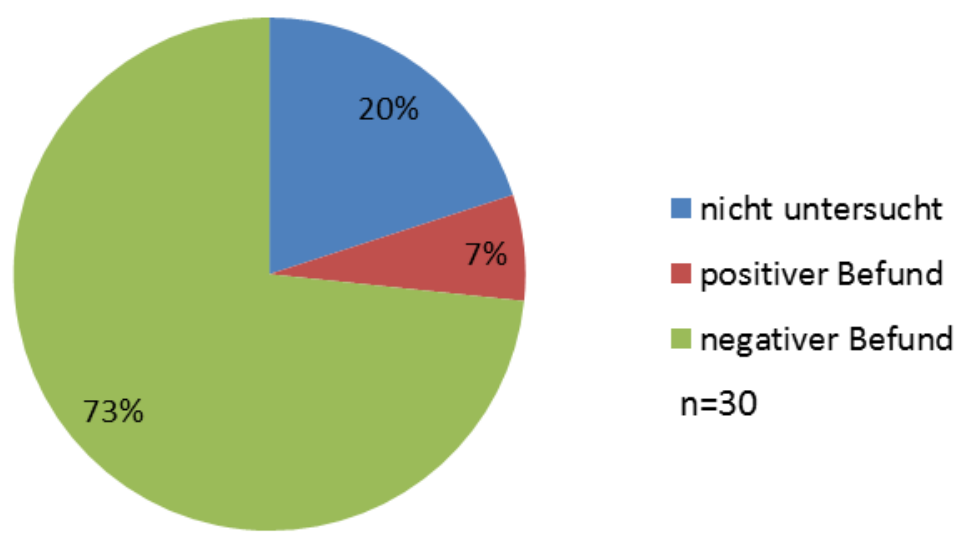

Abbildung 8: Ergebnis der Augenuntersuchung

In der folgenden Tabelle sind die erhobenen extrarenalen Symptome anhand der wichtigsten Register-Parameter untereinander verglichen.

Tabelle 5: Deskriptive Auswertung der extrarenalen Symptome

\begin{tabular}{|l|l|l|l|l|}
\hline \multirow{2}{*}{} & \multicolumn{2}{|c|}{$\begin{array}{c}\text { Innenohrbeteiligung } \\
\text { positiv }\end{array}$} & \multicolumn{2}{c|}{$\begin{array}{c}\text { Augenbeteiligung } \\
\text { nositiv }\end{array}$} \\
\hline \hline Fallzahl & $\mathrm{n}=12$ & $\mathrm{n}=17$ & $\mathrm{n}=2$ & $\mathrm{n}=22$ \\
\hline Stadium & $\begin{array}{l}\overline{\mathrm{x}}=2,42 \\
\text { Min/Max:0/4 } \\
\text { Median:2,5 }\end{array}$ & $\begin{array}{l}\text { Min/Max:0/3 } \\
\text { Median:2,0 }\end{array}$ & $\begin{array}{l}\text { Min/Max:2/3 } \\
\text { Median:2,5 }\end{array}$ & $\begin{array}{l}\text { Min/Max:0/4 } \\
\text { Median:2,0 }\end{array}$ \\
\hline Dialyse & $25 \%$ & 0 & 0 & $13,63 \%$ \\
\hline Therapie (ACEi) & $41,7 \%$ & $64,7 \%$ & $50 \%$ & $54,5 \%$ \\
\hline XLAS & $58 \%$ & $75 \%$ & $100 \%$ & $66 \%$ \\
\hline ARAS & $42 \%$ & $25 \%$ & 0 & $34 \%$ \\
\hline Alter & $\overline{\mathrm{x}}=47,17$ & $\overline{\mathrm{x}}=34,1$ & $\overline{\mathrm{x}}=52$ & $\overline{\mathrm{x}}=38,45$ \\
& $\begin{array}{l}\text { Min/Max:10/74 } \\
\text { Median:45 }\end{array}$ & $\begin{array}{l}\text { Min/Max:6/76 } \\
\text { Median:31 }\end{array}$ & $\begin{array}{l}\text { Min/Max:41/63 } \\
\text { Min/Max:6/76 }\end{array}$ & $\begin{array}{l}\text { Median:52 } \\
\text { Median:35,5 }\end{array}$ \\
\hline $\begin{array}{l}\text { Diagnosedauer } \\
\text { (Monate) }\end{array}$ & $\begin{array}{l}\overline{\mathrm{x}}=18 \\
\text { Min/Max:12/24 } \\
\text { Median:18 }\end{array}$ & $\begin{array}{l}\text { Min/Max:0/624 } \\
\text { Median:12 }\end{array}$ & $\begin{array}{l}\overline{\mathrm{x}}=112 \\
\text { Min/Max:12 }\end{array}$ & $\begin{array}{l}\overline{\mathrm{x}}=110 \\
\text { Min/Max:0/624 } \\
\text { Median:18 }\end{array}$ \\
\hline
\end{tabular}




\subsection{Prospektive Auswertung des Zeitraums 2011 bis 2014}

Zur prospektiven Analyse wurden 52 Datensätze ausgewertet. Der Verlaufszeitraum umfasst 46 \pm 10 Monate. Der Therapiezeitraum umfasst mit 8,4 $\pm 4,4$ Jahren (Median: 7 Min/Max: 2/18) einen deutlich längeren Zeitraum, da viele Patienten zum Startpunkt der Verlaufsbeobachtung schon unter Therapie standen und diese Daten bereits im bestehenden Register vermerkt sind. 2011 standen 57,69\% der Patienten (30/52) unter RAAS-Blockade, 96,3\% erhalten einen ACE-Hemmer. 3,3\% der Patienten(1/30) erhalten isoliert einen AT1-Blocker und 6,6\% (2/30) eine Kombination aus ACEi und AT1Blocker. Ein Patient erhält zusätzlich ein Statin. Im Vergleich dazu steigt die Zahl der unter Therapie stehenden Patienten im Jahr 2014 auf 65,38\% (34/52). 97,1\% von ihnen erhalten einen ACE-Hemmer. Gleichgeblieben ist die Anzahl derjenigen Patienten, welche isoliert mit einem AT1-Blocker behandelt werden. Die Anzahl der Kombinationstherapie steigt auf vier Patienten (11,8\%), drei Patienten erhalten zusätzlich zu der RAAS-Blockade ein Statin (8,8\%). Kein Patient hat die Behandlung abgebrochen. Ob die Einnahme der Medikamente passager unterbrochen wurde, ist nicht erfasst. Vier Patienten haben in dem Beobachtungszeitraum mit einer ACEi-Therapie begonnen.

Das mittlere Alter beim Erreichen des Endpunktes RRT liegt bei 42,9 $\pm 17,7$ Jahren (95\% KI: 26,5-59,2 Jahre). Lediglich unbehandelte Patienten haben diesen Endpunkt erreicht. Keiner der unter Therapie stehenden Patienten hat das Stadium der terminalen Niereninsuffizienz erreicht. Jedoch hat sich das Risiko, den Endpunkt RRT zu erreichen, in dem Beobachtungszeitraum 2011-2014 nicht wesentlich verändert.

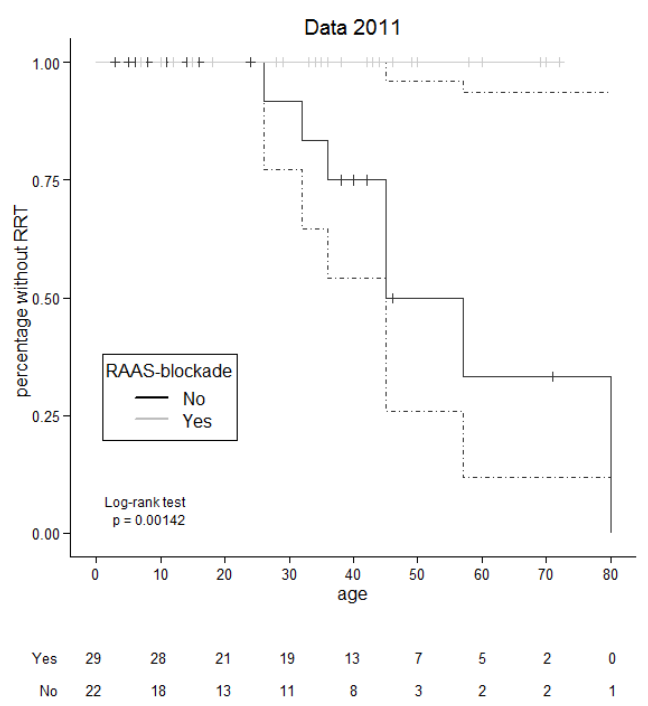

Abbildung 9: Kaplan-Meier-Schätzer Zeitpunkt 2011

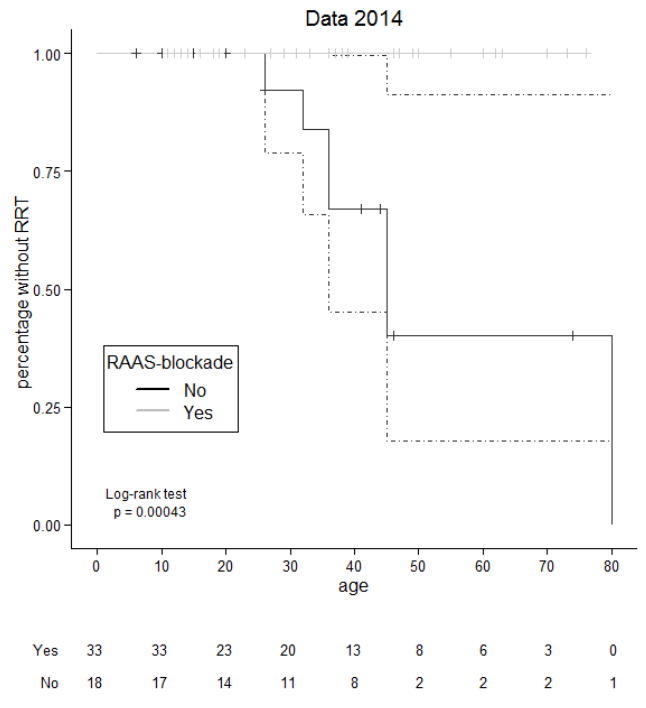

Abbildung 10: Kaplan-Meier-Schätzer Zeitpunkt 2014

2011 hatten 33\% der Patienten im Alter von 60 Jahren den Endpunkt RRT noch nicht erreicht. Im Vergleich zu dem Stichjahr 2014 ist der Anteil der Patienten, die noch nicht 
den Endpunkt erreicht haben, geringfügig um sieben Prozentpunkte (40\%) gestiegen. Alle Patienten ( $\mathrm{n}=7$ ), die dialysepflichtig sind, wurden folglich nie therapiert. Zwei Patienten sind in dem Beobachtungszeitraum verstorben.

\subsubsection{Therapie}

Bei $n=29$ unter Therapie stehenden Patienten konnte eine Auswertung über den Verlauf ihrer Nierenfunktion vorgenommen werden. Dabei zeigte sich, dass das untersuchte Patientenkollektiv in Bezug auf die Nierenfunktion in den vier Jahren der Verlaufsbeobachtung sehr stabil geblieben ist. Kein Patient hat sich in ein höheres Stadium entwickelt. Dagegen haben sich drei Patienten in ein prognostisch günstigeres Stadium entwickelt. Werden diese Patienten genauer betrachtet, zeigt sich, dass zwei Patienten, die sich 2011 im Stadium der fortgeschritten eingeschränkten Kreatinin-Clearance (Stadium 3) befanden, im Jahr 2014 eine Proteinurie $(3,45 \%, 1 / 29)$ beziehungsweise nur noch eine Mikroalbuminurie $(3,45 \%, 1 / 29)$ aufwiesen. Ein weiterer Patient $(1 / 29)$ konnte sein klinisches Stadium von der Proteinurie (Stadium 2) auf eine isolierte Hämaturie (Stadium 0) verbessern. Konstant ist die Anzahl jener Patienten geblieben, welche bereits 2011 das Stadium 2 aufzeigten (2011 und 2014 jeweils 55\%). Keiner dieser Patienten weist ein prognostisch ungünstigeres Stadium auf. Weder 2011 noch zum Endpunkt der Beobachtung 2014 war einer der unter Therapie stehenden Patienten mit der Erkrankung soweit fortgeschritten, dass eine Dialyse notwendig war.

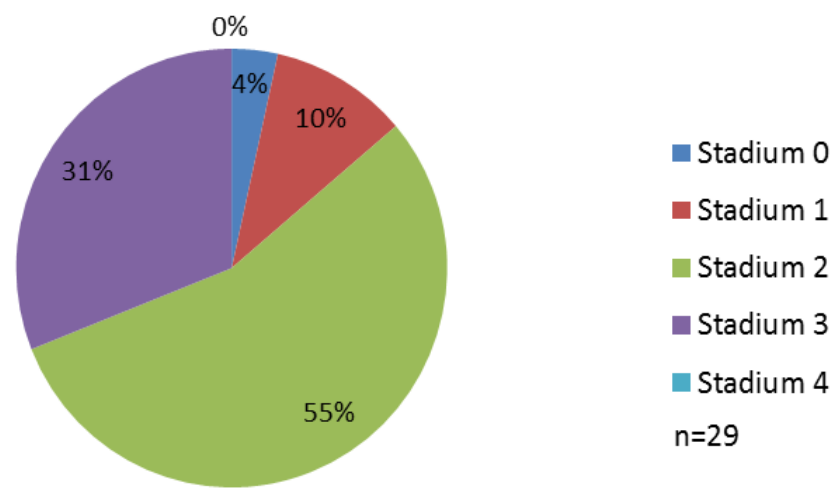

Abbildung 11: Stadienverteilung Therapiegruppe 2011 


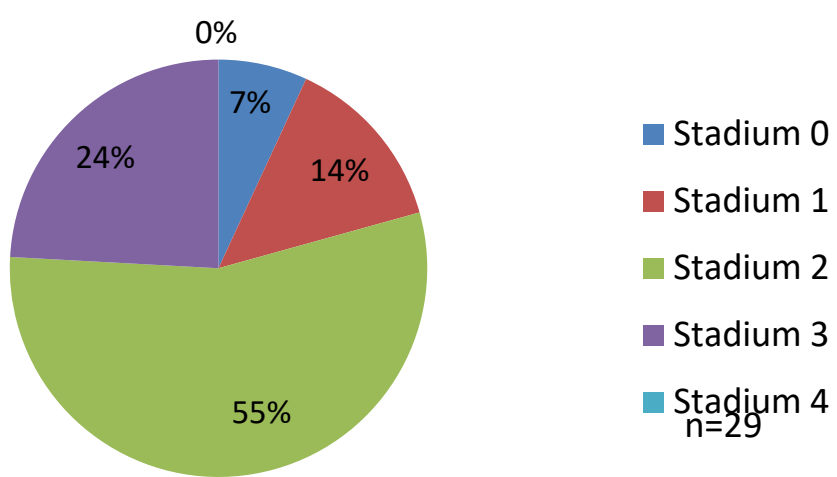

Abbildung 12: Stadienverteilung Therapiegruppe 2014

\subsubsection{Patienten ohne Therapie}

Wird die Gruppe der Patienten betrachtet, welche bislang nicht therapiert wurden (kurz: kT), so bleiben auch hier die Patienten überwiegend in ihrem Stadium stabil. Das Durchschnittsalter der Therapiegruppe beträgt 40 Jahre (Median: 38). Im Vergleich dazu steht die Gruppe der Nicht-Therapierten mit einem Durchschnittsalter von 39 Jahren (Median: 41). Alle dialysepflichtigen Patienten finden sich in der Nicht-Therapie-Gruppe wieder. Eine dialysierte Patientin ist in dem Beobachtungszeitraum verstorben und somit nun im Stadium 5. Bei der Auswertung der 18 Patienten zeigt sich eine zweigipflige Häufung. Neben dem Stadium 4 ist die Anzahl der Patienten in den Anfangsstadien 0 und 1 am häufigsten. Die Anfangsstadien des AS könnten der Grund sein, warum bei den betroffenen Kindern bisher nicht mit der Therapie begonnen wurde. Die Datenlage über einen sehr frühen Therapiebeginn ist aktuell noch nicht ausreichend, um eine Empfehlung abgeben zu können.

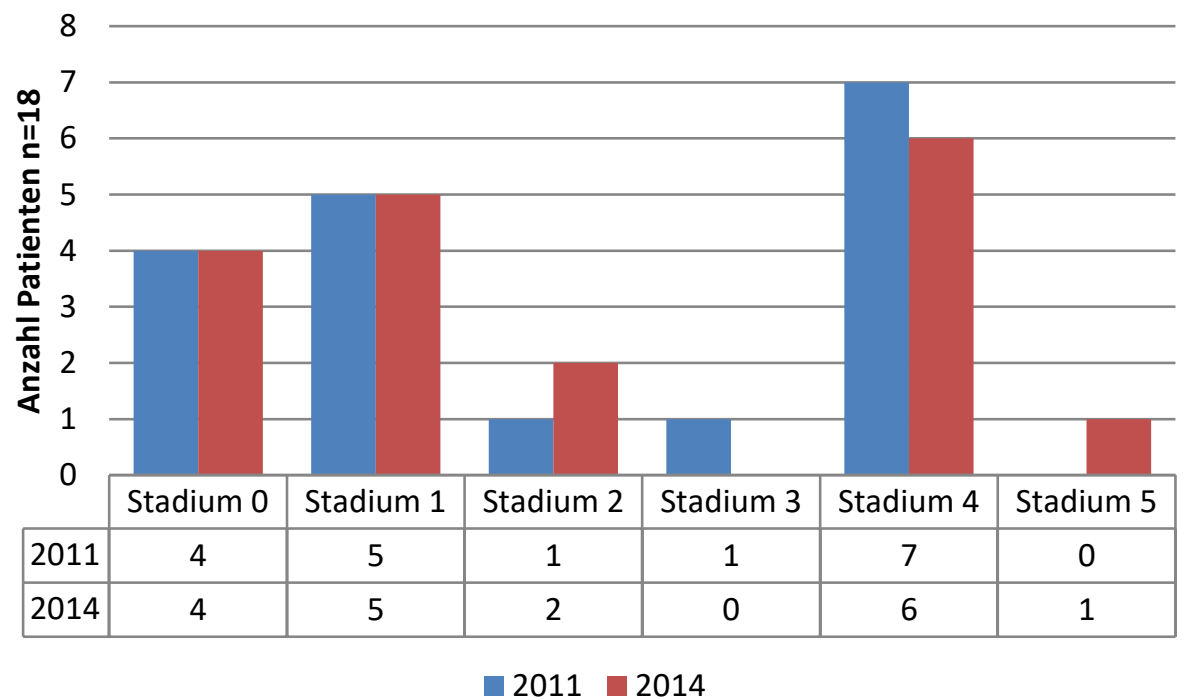

Abbildung 13: Stadienvergleich der Stichjahre 2011/2014 Gruppe ohne Therapie (kT) 


\section{Diskussion}

Das Anliegen dieser Arbeit ist es, den Effekt einer RAAS-Blocker-Therapie auf den Krankheitsverlauf von heterozygoten Mutationsträgern des AS darzustellen und zu analysieren. Erstmalig wurden dafür die im Alport-Register gelisteten Carrier über einen Zeitraum von fast vier Jahren prospektiv beobachtet. Bereits im Jahr 2011 wurde das Alport-Register erstmalig retrospektiv ausgewertet. Damals konnten Temme et al. zeigen, dass auch bei heterozygoten Mutationsträgern eine Therapie mit einer RAAS-Blockade den Endpunkt der terminalen NI verzögern kann. Dabei zeigte sich ein Therapiebeginn vor einer beginnenden Niereninsuffizienz als entscheidend (Temme et al. 2012). Darauf aufbauend erfolgte die aktuelle Auswertung des Registers, um einen langanhaltenden Effekt einer RAAS-Blockade bei Carriern des AS zu untersuchen. Der Effekt der ACEi-Therapie wird anhand der Entwicklung der Krankheitsstadien gemessen, wobei jeweils ein Anfangsund ein Endzeitpunkt des Stadiums erfasst wurde. Die individuelle Entwicklung der Nierenfunktion innerhalb des Beobachtungszeitraumes ist dabei nicht bekannt und auch etwaige individuelle Schwankungen innerhalb des Beobachtungszeitraums, z.B. der Kreatinin-Clearance, sind nicht erfasst. Da jedoch ein Ausgangswert (2011) und ein Endwert (2014) vorliegen, ist der Trend der Nierenfunktion ersichtlich. Viele Patienten wurden mit bereits laufender ACEi-Therapie im Jahr 2011 in das Register aufgenommen. So liegt der Beobachtungszeitraum bei etwa vier Jahren, jedoch reichen die Therapiespanne und somit die erfassten Daten zum Teil darüber hinaus.

Eine Schwäche einer reinen Beobachtungstudie ist es, dass nur zu einer begrenzten Anzahl an Zeitpunkten der Status quo erhoben werden kann. Die Zeiträume zwischen diesen Erfassungspunkten können auf diese Weise nicht gänzlich kontrolliert werden. Dies betrifft vor allem die Frage nach der kontinuierlichen Einnahme der Medikamente. Es ist also möglich, dass Patienten innerhalb des erfassten Zeitraumes die Therapie für Episoden (z.B aufgrund von Nebenwirkungen, Infekten, Schwangerschaft...) unterbrochen haben. Die Einnahme eines ACEi ist nicht immer unproblematisch und gerade bei weiblichen Patientinnen mit Einschränkungen verbunden. Eine besondere Herausforderung bei der Therapie von Frauen mit ACEi ergibt sich aus der Tatsache, dass diese bei einer Schwangerschaft kontraindiziert sind. Es kommt also bei Kinderwunsch zwangsläufig zu einer Unterbrechung der Therapie. Auch nach der Schwangerschaft ist eine Wiederaufnahme der Therapie nicht hundertprozentig sichergestellt und es kommt zu längeren Pausen bei der Therapie. Das AS zu therapieren bedeutet eine lebenslange Einnahme von Medikamenten. Diese Erkenntnis könnte zu einer verringerten Compliance, insbesondere bei jungen Patienten, führen. Nebenwirkungen von ACEi sind selten, können aber ebenfalls zu einem Abbruch der Therapie führen. Über die Dosierung der ACEiTherapie liegen uns keine Daten vor. In einer älteren Auswertung der Alport-Registers von Gross et al. wurden Ramipril und Enalapril in einer Dosierung von 0,025-0,1 mg/kg 
Körpergewicht bzw. 0,125-1,0 mg/kg Körpergewicht als die häufigsten ACEi verwendet (Gross et al. 2012b).

Bei der Auswahl der Patienten für die Verlaufsauswertung wurden nur vollständige Datensätze für beide Stichjahre berücksichtigt, so dass ein nicht unerheblicher Anteil der Patienten, welche 2011 ausgewertet wurden, nicht in der aktuellen Arbeit berücksichtigt werden konnte. Dies betrifft vor allem die Patienten aus dem Ausland (Frankreich, Spanien, Belgien). Diese konnten aus Gründen der Patientensicherheit und Datenübermittlung nicht weiter verfolgt werden. Der lost of follow-up-Effekt ist auch durch einen Wechsel der behandelnden Ärzte begründet: Solche Patienten, die mit der Volljährigkeit aus dem Zuständigkeitsbereich der Kindernephrologen oder Pädiater gelöst wurden und sich eventuell noch keinen neuen Arztkontakt gesucht haben oder deren Arztwechsel nicht bekannt ist, fallen aus der Betrachtung heraus. Dieses Problem wird unter dem Begriff der Transitionsmedizin zusammengefasst. Im Bereich des AS hat diese Transitionsproblematik bisher nur wenig Beachtung gefunden und ist natürlich bei der Seltenheit des AS eine Herausforderung. Jedoch ist gerade ein fließender Übergang der zuständigen Ärzte wichtig um Unterbrechungen der Therapie zu verhindern. Es ist wichtig, dass Carrier auch in Phasen des subjektiven Wohlbefindens unter regelmäßiger Kontrolle bleiben um ein Voranschreiten der Erkrankung zu erkennen und womöglich eine Therapie zu beginnen, auch wenn die Patienten keinen Leidensdruck verspüren.

\section{Die Entwicklung der Nierenfunktion bei heterozygoten Mutationsträgern}

Das mittlere Alter bei Erreichen der terminalen Niereninsuffizienz bei den von uns ausgewerteten Carriern beträgt 42,9 Jahre. Beim Vergleich der Literatur zeigt sich hier eine große Spanne von Ergebnissen. Eine finnische Studie beschreibt ein mittleres Alter von 31,1 Jahren, also ein Auftreten des terminalen Nierenversagens bei durchschnittlich zehn Jahre jüngeren Patienten (Pajari et al. 1996). Ein Grund dieser Differenz könnte die in der Zwischenzeit etablierte Off-Label-Therapie mittels einer RAAS-Blockade sein. Dies könnte das spätere Auftreten des Endpunktes begründen, so dass dieser Effekt in der fast zwanzig Jahre später durchgeführten Auswertung durchaus sichtbar werden könnte. Allerdings weist die Arbeit von Panjari et al. darauf hin, dass der Vergleich der Ergebnisse kritisch zu hinterfragen ist, da die Diagnostikkriterien nicht einheitlich sind. Nur wenige der in der o.g. Studie eingeschlossenen Patienten wurden mittels einer Biopsie diagnostiziert. Eine Gendiagnostik war damals noch nicht möglich. Dagegen ist diese heute mehr und mehr Standard und erlaubt eine spezifische Diagnostik. Die Auswertung der medianen Überlebenszeit mittels des Kaplan-Meier-Schätzers kommt bei unserer Auswertung zu dem Ergebnis, dass 44\% der nicht therapierten Patienten den Endpunkt RRT im Alter von 60 Jahren erreicht haben. Es zeigt sich ab dem Alter von 40 Jahren ein signifikant erhöhtes Risiko dialysepflichtig $\mathrm{zu}$ werden. Eine der größten Auswertungen eines Patientenkollektives mit dem Carrier-Status kommt zu dem Ergebnis, dass das Risiko der terminalen NI ab einem Alter von 60 Jahren signifikant steigt (Jais et al. 2003). In dieser 
großen Übersichtsstudie wurde gezeigt, dass im Alter von 40 Jahren lediglich $12 \%$ der Carrier ein terminales Nierenversagen aufweisen, mit 60 Jahren und mehr ein 30 - bis 40\%iges Risiko besteht den Endpunkt der Niereninsuffizienz zu erreichen. Daten von Flinter et al. (1988) konnten eine terminale Niereninsuffizienz bei 15\% der Frauen aufweisen. Eine ebenso ältere Studie kommt bei der Auswertung auf eine Rate von 13\% der Frauen, die den Endpunkt ESRD erreichen (Hasstedt et al. 1986). Eine ebenso niedrigere Rate von 8\% ist in der Studie von Dagher et al. aufgeführt (Dagher et al. 2001). Jedoch sind $43 \%$ der Patienten mit dem XLAS in dieser Kohorte jünger als 20 Jahre. Im Vergleich sind dies in unserer Auswertung lediglich etwa 25\% der Patienten. Mit diesem Übergewicht an jüngeren und in ihrem Krankheitsverlauf noch weniger weit fortgeschrittenen Carriern besteht das Risiko einer Verzerrung der Ergebnisse gerade bei der Auswertung der Endpunkte.

Mit einem Alter von 30 Jahren weisen fast alle der Carrier eine noch uneingeschränkte Nierenfunktion auf (Flinter et al. 1988). Dies gleicht unseren Daten, bei denen mit 30 Jahren lediglich 8\% der Patienten den Endpunkt RRT erreicht haben. Jedoch zeigen unsere Daten, dass Patienten mit dem Alter von 40 Jahren ein etwa 33\%iges Risiko des terminalen Nierenversagens haben. Ähnlich hohe Ergebnisse konnte eine Studie von Grünfeld et al. (1985) aufzeigen, bei der das Risiko der Niereninsuffizienz mit dem Alter von 35 Jahren bei $40 \%$ liegt. Es liegt nahe, dass auch unsere Daten das Risiko des Erreichens der terminalen Niereninsuffizienz aufgrund einer nicht zu beeinflussenden Selektion überschätzen. Das der Arbeit zu Grunde liegende Register beinhaltet tendenziell vor allem die symptomatischen Patienten mit ausgeprägtem Krankheitsbild, welche sich regelmäßig in ärztliche Kontrolle begeben. Patienten mit oligo-symptomatischem Verlauf und ohne großen Leidensdruck können dagegen nur schwer erfasst werden, da ein Arztkontakt seltener oder nur bei deutlicher Verschlechterung stattfindet. Ebenso gehen der Auswertung Patienten verloren, die nicht mehr kontaktierbar sind oder keine regelmäßigen Kontrollen durchführen lassen.

Im Vergleich der Jahre 2011 und 2014 ist das Risiko den definierten Endpunkt einer behandlungsbedürftigen Niereninsuffizienz zu erreichen leicht vermindert, jedoch nicht signifikant zu messen. Die Gründe hierfür könnten ein Erfolg der bestehenden ACEiTherapie oder eine schnellere und verbesserte Diagnostik und somit ein rechtzeitiger Therapiebeginn sein. Dennoch kann es aufgrund der im Vergleich zum Krankheitsverlauf kurzen Auswertungsspanne auch ein Zufallsergebnis sein.

Wird die Nierenfunktion und der Endpunkt der terminalen NI in Bezug auf die zwei vorliegenden Erbgänge (XLAS und ARAS) hin untersucht, zeigt sich ein deutlicher Unterscheid bei dem Erreichen des Endpunktes. Mit einem Alter von 60 Jahren sind 16\% der Patienten mit XLAS dialysepflichtig. Bei den Patienten mit ARAS befinden sich zu dem Zeitpunkt jedoch bereits 37\% an der Dialyse. Klassischerweise weisen Carrier für das ARAS auch eine Hämaturie auf, entwickeln aber seltener eine terminale NI. In unserem 
Register sind vor allem jene Carrier aufgenommen, die symptomatisch sind und einen ausgeprägten Krankheitsverlauf aufweisen. Heterozygote Träger, die bisher nicht diagnostiziert sind, fehlen naturgemäß in unserem Register.

\section{Der Effekt einer RAAS-Blockade bei heterozygoten Mutationsträgern.}

Eine der Kernfragen der Auswertung war, wie sich das Krankheitsstadium der Carrier innerhalb der untersuchten vier Jahre unter der Therapie mit ACEi verändert. Unsere Verlaufsstudie konnte zeigen, dass die heterozygoten Carrier von einer RAAS-Therapie profitieren. Über den Zeitraum von fast vier Jahren sind alle ausgewerteten Patienten in ihrem Krankheitsstadium stabil geblieben. In einer großen Verlaufsstudie über männliche Alport-Patienten konnte eine signifikante Verlängerung des Intervalls bis zum Eintreten der terminalen Niereninsuffizienz beobachtet werden (Gross et al. 2012b). Es ist anzunehmen, dass es auch bei heterozygoten Mutationsträgern unter einer Therapie mit Blockade des RAAS zu einer Stabilisierung des Krankheitsverlaufes kommt. Auf der anderen Seite ist der Zeitraum von vier Jahren zu kurz, um nicht auch ein Persistieren des Krankheitsverlaufes unabhängig von einer Therapie auszuschließen. Auch wenn sich gerade bei den Carriern zwar eine Affektion der Nierenfunktion in Form einer Hämaturie oder Proteinurie zeigt, wird jedoch das Fortschreiten bis hin zur terminalen Niereninsuffizienz weitaus seltener beobachtet. Dennoch zeigen auch diejenigen Patienten keine Verschlechterung, bei denen die Therapie erst bei schon eingeschränkter Nierenfunktion begonnen wurde. Erstaunlich ist, dass die Krankheitsstadien dieser Patienten nicht nur stabil geblieben sind, sondern in wenigen Fällen sogar einen regredienten Verlauf zeigen. Dies unterstützt die Annahme einer positiven Auswirkung der Therapie mit ACEi auch bei den Carriern des AS. Eine Verbesserung der Nierenfunktion konnte auch eine Studie von Daina et al. 2015 nach weisen. Hier kam es bei sechs von acht Patienten unter einer Kombinationstherapie aus ACEi, AT1-Blocker, Kalzium-KanalInhibitor und einem Statin zu einer Verbesserung in Bezug auf die Proteinurie (Daina et al. 2015).

Der Anteil der unter Therapie stehenden Patienten im Register steigt in dem beobachteten Zeitraum von 2011 bis 2014 von 58\% auf 65\%. Diese Zunahme könnte darauf beruhen, dass in den letzten Jahren die Erkenntnisse über den Krankheitsverlauf bei heterozygoten Mutationsträgern zugenommen haben. Dadurch wird zunehmend auch dieser betroffenen Gruppe des AS ein frühzeitiger Start der Therapie empfohlen. Dabei konnte in einer Verlaufsstudie der positive Effekt einer RAAS-Blockade bei Carriern des AS aufgezeigt werden (Temme et al. 2012).

Die Mehrheit der therapierten Carrier befindet sich im Stadium der Proteinurie, also eben jenem Merkmal, bei der die Empfehlung zum Therapiebeginn mittels einer RAASBlockade gegeben wird. Dennoch haben etwa ein Viertel der Carrier eine ACEi-Therapie in einem Stadien begonnen, in dem es noch nicht zu einer Proteinurie gekommen ist. Die 
Datenlage zu einer frühen Therapie ist nach wie vor begrenzt. Gerade bei Kindern wird sehr vorsichtig mit der Gabe von ACEi umgegangen. Als eine Off-Label-Therapie bedarf jeder Einsatz von ACEi einer individuellen Abwägung. Einfacher gestaltet sich die Entscheidung bei Erwachsenen, da hier für Wirkung und Nebenwirkung von ACEi sehr gute Daten vorliegen und so die Entscheidung für die Gabe von ACEi schneller erfolgt.

In einem auf dieser Auswertung beruhenden Paper von Stock et al. werden Szenarien diskutiert, welche den frühen Start einer RAAS-Blockade begünstigen könnten:

1.) Ein ACEi wird aufgrund eines kardiovaskulären Ereignisses oder zur Hypertoniebehandlung gegeben.

2.) Der Patient entwickelt passager eine Proteinurie, z.B. aufgrund eines Infektes. Eine Therapie wird eingeleitet und diese beibehalten. Da unser Register nur den Anfangs- und Endwert des Nierenstatus erfasst, ist es möglich, dass es in dem Zeitraum von 2011 bis 2014 bei einigen Patienten zu einer zwischenzeitlichen Proteinurie gekommen ist.

3.) Es sind weitere Familienmitglieder betroffen und das Bewusstsein gegenüber der Erkrankung und der Therapiemöglichkeiten ist gesteigert. So könnten die Eltern bei einem betroffenen Kind den frühzeitigen Beginn einer Therapie wünschen (Stock et al. 2015).

Unsere Arbeit weist eine deutliche Diskrepanz zwischen der Therapiegruppe und der Nicht-Therapiegruppe bezüglich der Entwicklung der terminalen NI auf. Interessanterweise befinden sich beide Gruppen mit einem Durchschnittsalter von 40 Jahren bei der Therapiegruppe beziehungsweise mit 39 Jahren bei der nicht therapierten Gruppe zum Auswertungszeitpunkt 2014 in jener Altersgruppe, bei der das Risiko der terminalen NI signifikant steigt. Jedoch zeigt die Gruppe der Patienten ohne Therapie eine größere Altersstreuung, da sich in dieser Gruppe auch alle dialysepflichtigen Patienten, mit einem Durchschnittsalter von 51 Jahren, befinden. Ein nächster Schritt wäre es, die Gruppe der unter ACEi-Therapie stehenden Patienten über einen Zeitraum weiter zu verfolgen, der über den Zeitpunkt des erhöhten statistischen Risikos hinausgeht.

Bei der Auswertung der Patienten, die bisher nicht therapiert wurden, zeigen sich zwei Gruppen. Zum einen die Patienten, die schon das Stadium der terminalen Niereninsuffizienz erreicht haben und bei denen eine ACEi-Therapie keine Konsequenz hinsichtlich der Nephroprotektion hätte. Zum anderen die Patienten, die sich in dem Krankheitsverlauf noch in frühen Stadien befinden. Auch diese Patienten zeigten innerhalb der ausgewerteten vier Jahre eine Persistenz der Nierenfunktion. Bei diesen Patienten kam es innerhalb des von uns relativ kurzen Beobachtungszeitraums zu keinem Fortschreiten des AS. Dabei ist die Aussagekraft bei der geringen Anzahl der Patienten im Vergleich zu der Therapiegruppe vermindert und es kann somit leichter zu einer Verzerrung der Ergebnisse kommen. Jedoch ist das Risiko eines Progresses der Erkrankung gegeben, wenn auch bekanntlich langsamer als bei den Vollträgern des AS. Dass diese Patienten bisher nicht therapiert wurden, könnte daran liegen, dass es bei den Empfehlungen zum Start 
einer ACEi Therapie bisher nur Daten zum Therapiebeginn mit Beginn der Proteinurie gibt. Es herrscht eine Unsicherheit in Bezug auf die Therapie des Alport-Syndroms in bereits frühen Stadien wie der Hämaturie. Dies könnte ein Grund dafür sein, dass ein Großteil der Patienten in eben diesen frühen Stadien nicht therapiert ist. Um die Datenlage $\mathrm{zu}$ verbessern, befindet sich aktuell die EARLY-PROTECT-Studie in der Behandlungsphase. Hier soll der Effekt einer frühen ACEi-Therapie aufgezeigt werden (Gross et al. 2012a). Alle Patienten, die sich in der terminalen Niereninsuffizienz befinden und auf ein Nierenersatzverfahren angewiesen sind, wurden in dem Zeitraum von der Diagnosestellung bis zur Dialyse nicht therapiert. Hierfür könnten folgende Gründe verantwortlich sein: Bei dem Patienten wurde das AS bereits in einem solch fortgeschrittenen Stadium diagnostiziert, dass eine Therapie keine Konsequenz mehr gehabt hätte. Ein anderer Grund wäre, dass die Notwendigkeit einer Therapie vor Eintritt der Dialysepflichtigkeit verkannt wurde oder der Arzt sich ihrer nicht bewusst war.

Ein großes Problem stellt die Tatsache dar, dass heterozygote Mutationsträger lange Zeit bei den Überlegungen und Empfehlungen zur Therapie des Alport-Syndroms nicht ausreichend beachtet wurden. Lange Zeit wurde der Carrier-Status als ein benigner charakterisiert und unter dem Begriff der benignen familiären Hämaturie untergeordnet. Hier besteht die Gefahr, dass Patienten, die unter der Diagnose TBMN laufen, nicht die eigentliche Diagnose des AS bekommen, die für die Nephropathie verantwortlich sein kann (Savige et al. 2013). Erst jetzt wächst zunehmend das Bewusstsein dafür, dass auch die heterozygoten Mutationsträger von einer Therapie profitieren können. Die wachsenden Erkenntnisse über den langfristigen Nutzen einer RAAS-Blockade, wie er in dieser Auswertung bestätigt werden konnte, sollten dazu führen, dass Betroffene über die Möglichkeit einer Therapie mit dem Ziel einer Verlangsamung des Krankheitsprogresses informiert werden. Für die Durchführung dieser Therapie ist eine erfolgreiche Transition der Patienten notwendig und sicher noch ausbaufähig.

\section{Die Herausforderung der Diagnosestellung}

Bei der Auswertung der Daten zur Zeitspanne vom Auftreten des ersten Symptoms bis zur Diagnosestellung wird deutlich, dass die Diagnosestellung gerade bei heterozygoten Carriern nach wie vor eine Herausforderung darstellt. Im Mittel dauerte es acht Jahre, bis die Diagnose AS gestellt werden konnte. In einer Arbeit von Jais et al. (2003), wird das Alter bei Diagnosestellung mit einer breiten Streuung von einem Tag bis 57 Jahren angegeben. Eine Hämaturie tritt bei fast allen heterozygoten Mutationsträgern im Laufe der Erkrankung auf (Jais 2003). Es stellt sich die Frage, wann die ersten Symptome auffallen und wie die Entscheidung getroffen wird diese abzuklären und vor allem, welcher Facharzt die erste Anlaufstelle ist. An einer kleinen Gruppe von Patienten wird ersichtlich, dass der Zeitraum vom Auftreten je nach Art des zuerst beobachteten Symptoms bis zur Diagnosestellung unterschiedlich lang ausfällt. So dauerte es bei Patienten, die mit einer 
Makrohämaturie klinisch auffällig geworden waren, am kürzesten, bis die Diagnose AlportSyndrom gestellt wurde. Patienten mit Befunden, die nicht mit bloßem Auge ersichtlich sind wie eine Mikrohämaturie oder Proteinurie, bekamen erst deutlich verzögert ihre definitive Diagnose. Idealerweise sollte das Alport-Syndrom möglichst im frühen Stadium diagnostiziert werden um eine Therapie einleiten zu können. Ist es bereits zur Proteinurie gekommen, ist bereits wertvolle Zeit für eine Therapie verloren gegangen. So zeigt sich bei den Patienten, die mit einer Proteinurie auffällig wurden, ein Diagnosezeitraum mit einer Spanne von einem bis zu 30 Jahren. Eine zusätzliche Beteiligung des Ohres ist bei nahezu der Hälfte dieser Patienten nachzuweisen. Dieses Ergebnis betont die besondere Wichtigkeit einer interdisziplinären Diagnostik.

Die Mikrohämaturie kann nur durch eine gezielte Untersuchung oder bei einer RoutineUrindiagnostik bestimmt werden. So sollte bei positiver Familienanamnese eine Untersuchung der Familienmitglieder stattfinden, wobei dann zum Beispiel eine Mikrohämaturie auffallen würde. Ein Urinstix ist eine kostengünstige und schnelle Diagnostikhilfe für Routineuntersuchungen beim Hausarzt oder bei betrieblichen Vorsorgeuntersuchungen. Die schnelle und gezielte Diagnose des AS ist auch heute noch ein Problem. Dies gilt insbesondere für die Diagnose heterozygoter Mutationsträger. Hier ist eine Sensibilisierung der behandelnden Ärzte zu wünschen, um bei der Abklärung einer Hämat- oder Proteinurie das AS trotz seiner Seltenheit frühzeitig als Differentialdiagnose in Erwägung zu ziehen.

\section{Die Auswirkung von extrarenalen Manifestationen auf den Krankheitsverlauf}

Die Datenauswertung zu den extrarenalen Symptomen zeigte einen signifikanten Zusammenhang zwischen einer Hypakusis und der terminalen Niereninsuffizienz. So zeigten etwa 41\% der Patienten einen auffälligen Hörbefund. Dies liegt deutlich höher als in der Auswertung von Jais et al. (2003) ( 28\%). Von unseren Patienten mit einer Ohrbeteiligung haben 25\% den Endpunkt RRT erreicht. Auch hier könnte die unfreiwillige Selektion der Patienten zu einer Verzerrung der Ergebnisse führen, denn 15-20\% der Patienten haben bisher keine Abklärung einer Hör- und Augenbeteiligung erhalten. Dies kann an einer mangelnden Anbindung an einen Facharzt liegen oder an einem fehlenden Bewusstsein der Ärzte und Betroffenen für die Wichtigkeit dieser Diagnostik. Mit 47 Jahren waren die Patienten zwar älter als der Durchschnitt der untersuchten Kohorte, jedoch mit 47 Jahren in einem Lebensalter, in der die Presbyakusis eine untergeordnete Rolle spielt (Yamasoba et al. 2013). Generell gilt das Auftreten von extrarenalen Symptomen, insbesondere die Beteiligung des Innenohrs, als Risikofaktor für einen fulminanten Verlauf des Alport-Syndroms (Jais 2003). Umso interessanter ist das Ergebnis zu werten, dass bei einem Großteil der Carrier bisher keine Abklärung der Augen- und Hörbeteiligung erfolgt ist. Ein frühzeitiges Erkennen einer extrarenalen Mitbeteiligung würde möglicherweise einen zeitigeren Therapiebeginn begünstigen. 
Eine Beteiligung der Augen wiesen nur 7\% der Carrier auf. Dies liegt unter dem Ergebnis von 15\% in der Auswertung von Jais et al. (2003). Dabei erfasst das ausgewertete Register nicht die genauen Augenuntersuchungen und -diagnosen. Allerdings ist auch die Sensitivität der Untersuchung der Augenveränderungen nicht bei 100\% und evtl. werden kleine Veränderungen nicht erkannt oder nicht dem AS zugeordnet. Die Ergebnisse zeigen, dass eine Augenbeteiligung seltener als die Hörbeeinträchtigung vorkommt. Dennoch können beide extrarenalen Veränderungen, sofern eine frühzeitige Abklärung erfolgt, zu einer schnelleren definitiven Diagnose führen. So gilt insbesondere bei Carriern die periphere Retinopathie als hilfreiches Diagnostikkriterium (Shaw et al. 2007). Generell stehen der anteriore Lentikonus, die zentrale sowie die periphere Retinopathie als Affektion beim AS im Vordergrund. Der Lentikonus tritt häufiger bei den Trägern des AS auf. Carrier weisen eher eine Retinopathie auf, wenn eine Beteiligung des Auges vorliegt (Savige et al. 2010).

Bei der Diagnostik von extrarenalen Manifestationen des AS stellen sich zwei Probleme dar: Zum einen muss der Schritt zum richtigen Facharzt unternommen werden und zum anderen müssen die teilweise sehr spezifischen Veränderungen auch rechtzeitig erkannt werden. Hier ist es sicherlich in Zukunft wichtig ein noch größeres Bewusstsein für den Stellenwert der Diagnostik der extrarenalen Veränderungen zu schaffen.

\section{Stellenwert der Nierenbiopsie}

Bei lediglich 7,2\% der Carrier wurden Nierenbiopsien durchgeführt. Im Vergleich ergab die Auswertung der Biopsieergebnisse bei den Trägern des AS mit über $90 \%$ eine wesentlich höhere Rate (eigene unveröffentlichte Daten aus der Arbeitsgruppe von Gross et al.). Mit einer Nierenbiopsie besteht die Möglichkeit, das Ausmaß der Schädigung in den Glomeruli direkt beurteilen zu können. Histologisch zeigt sich im lichtmikroskopischen Präparat nur ein unspezifisches Bild, bei dem nicht auf den auslösenden Schädigungsmechanismus geschlossen werden kann. Genauer, und daher lange Zeit der Goldstandard der Diagnostik ist es, ein elektronenmikroskopisches (EM) Präparat anzufertigen. Dies ist jedoch ein wesentlich aufwendigerer Schritt im Vergleich zur Herstellung eines lichtmikroskopischen Präparates. Jedoch lassen sich nur unter dem Elektronenmikroskop die charakteristischen Veränderungen der Basalmembran erkennen, so dass der Prozess der Krankheit beurteilt werden kann. Die GBM ist bei Carriern ausgedünnt. Es kommt aber zu Stellen mit einer Lamellierung und auch Verdickungen der GBM. Bei der Abgrenzung eines XLAS-Carrier-Status von der TBMN stellt die EMDiagnostik eine wichtige Methode dar (Savige et al. 2003). Dennoch ist die Nierenbiopsie ein invasives Diagnosemittel und der Einsatz bei Kindern heutzutage kritisch zu hinterfragen. Wenn eine Biopsie durchgeführt wird, sollte zur Erhöhung der Aussagekraft die Auswertung möglichst mittels EM durchgeführt werden. Aktuell wird der Stellenwert der Diagnostik auf Basis einer Biopsie diskutiert (Gross et al. 2016), denn mittlerweile ist 
die genetische Diagnostik technisch weit fortgeschritten, in allen Zentren zugänglich und finanziell erschwinglich geworden. Generell ist die Gendiagnostik eine effiziente und sehr sensitive Methode, mit der auch heterozygote Mutationsträger schon in frühen Stadien entdeckt werden können (Adam et al. 2013).

Die genetische Diagnostik erweist sich daher zunehmend als führende Methode zur Sicherung des AS. In einer Arbeit von Yao et al. konnte gezeigt werden, dass eine nicht unerhebliche Rate an Fehldiagnosen anhand der alleinigen lichtmikroskopischen Diagnostik gestellt wurden. Dabei stellt die FSGS die häufigste histologische Diagnose dar (Yao et al. 2012). Dies spiegelt sich auch in unseren Daten wider. Bei elf Patienten aus dem Register lag ein Befund des lichtmikroskopischen Präparates vor. Es zeigte sich nahezu in der Hälfte der Fälle eine fokal segmentale Glomerulosklereose im entsprechenden Präparat. Fünf Präparate davon wiesen lichtmikroskopisch keine Pathologien auf, obwohl die Mutationen im Kollagen IV vorhanden waren. Bei den fünf Patienten liegt maximal eine Proteinurie vor und womöglich eine noch unbeeinträchtigte Struktur der Glomeruli. Besonders Frauen profitieren von der Möglichkeit der genetischen Diagnostik, da bei ihnen die Klinik, die Familienanalyse und die Biopsie oft nicht wegweisend sind (Adam et al. 2013).

\section{Nebenwirkungen der Therapie}

Die Verträglichkeit von ACEi ist im Allgemeinen sehr gut und es kommt nur selten zu Nebenwirkungen wie Reizhusten, Hypotonien oder Elektrolytverschiebungen. Vor allem der Reizhusten als Nebenwirkung wird von der Fachinformation als häufiges $(\geq 1 / 100$ bis $<1 / 10$ ) Ereignis eingestuft (Karow und Lang 2012). Dennoch ist auch in dem hier ausgewerteten Patientenkreis nur eine Person abgebildet, die einen AT1-Blocker erhält, wobei nicht bekannt ist, ob dieser aufgrund von Nebenwirkungen des ACEi verschrieben wurde. Generell wird ein ACEi als First-Line-Therapie des AS empfohlen, so dass in dem vorliegenden Fall durchaus von einem Nebenwirkungs-induziertem Wechsel des Präparates ausgegangen werden kann.

\section{Statine in der Therapie des Alport-Syndroms}

Vier Patienten der Therapiegruppe erhalten zusätzlich zu der RAAS-Blockade ein Statin. Es ist nicht erfasst, aus welcher Indikation heraus, und wie lange die Einnahme des Statins erfolgt. Es ist aber bekannt, dass HMG-CoA-Inhibtoren neben der Cholesterinsenkung auch pleiotrope Effekte aufweisen. In einer Arbeit von Koepke et al. konnte in einem Mausmodell gezeigt werden, dass mit einem Statin behandelte Alport-Mäuse ein längeres Überleben und eine verringerte Proteinurie aufwiesen (Koepke et al. 2007). Aufgrund der sehr kleinen Anzahl an Daten konnte keine signifikante Auswertung dieser Daten bezüglich 
der Effekte einer Kombinationstherapie vorgenommen werden. Hierzu wäre eine größere Kohorte von Patienten notwendig. 


\section{$5 \quad$ Zusammenfassung}

Das Alport-Syndrom (AS) ist eine hereditäre Erkrankung, die durch Mutationen im Kollagen IV zu einem fortschreitenden Funktionsverlust der glomerulären Basalmembran führt, aber auch mit extrarenalen Symptomen wie einer Schwerhörigkeit und Augenveränderungen einhergeht. Durch das vorherrschende X-chromosomale Vererbungsmuster wird das AS in seiner vollen Ausprägung vor allem bei männlichen Patienten diagnostiziert. Dennoch weisen alle Überträger (Carrier) der Mutation mit ihrem heterozygoten Status ebenfalls ein Risiko auf, eine terminale Niereninsuffizienz zu entwickeln. Nicht-interventionelle Beobachtungsstudien konnten zeigen, dass das Voranschreiten der Niereninsuffizienz medikamentös verlangsamt und damit auch der Beginn einer terminalen Niereninsuffizienz signifikant verzögert werden kann. Als FirstLine wird die Off-Label-Therapie mit einem ACE-Hemmer (ACEi) empfohlen. Die Evidenzlage für die RAAS-Blockade ist dabei bei den vorrangig männlichen Trägern des AS am besten. Heterozygote Mutationsträger standen lange Zeit nicht im Fokus der Forschung und deren Krankheitsverlauf wurde häufig als benigne eingestuft. Diese Annahme gilt zu Unrecht, denn obwohl Carrier oft einen langsameren und lange Zeit symptomfreien Krankheitsverlauf aufweisen, können sie dennoch von der vollen Ausprägung des AS betroffen sein.

Der potentielle Nutzen einer frühzeitigen nephroprotektiven Therapie konnte bereits in retrospektiven Studien auch bei diesen heterozygoten Mutationsträgern nachgewiesen werden. Der Ansatz meiner Arbeit war es daher, darauf aufbauend eine prospektive Auswertung über einen möglichst langen repräsentativen Zeitraum von über vier Jahren durchzuführen. Dazu konnten bei einer Patientengruppe von 65 heterozygoten Mutationsträgern retrospektive Daten über die Therapie durch eine RAAS-Blockade ausgewertet werden. Die Datenauswertung wurde von der Annahme geleitet, dass es einen deutlichen und langfristigen positiven Effekt dieser RAAS-Blockade auf das Fortschreiten der Erkrankung gibt. Kernpunkt der vorliegenden Arbeit ist der Vergleich zwischen einer therapierten und einer nicht-therapierten Gruppe von Carriern aus dem europäischen Alport-Register.

Als wichtigster Punkt meiner Datenauswertung konnte gezeigt werden, dass die TherapieGruppe keinen Progress der Erkrankung aufweist und in wenigen Fällen sogar eine Verbesserung der Nierenfunktion eintrat. Erstmals konnte damit auch prospektiv gezeigt werden, dass die Therapie mit ACEi auch bei Carriern zu einer Stabilisierung des Verlaufs 
des AS führt. Den Endpunkt einer Dialysepflichtigkeit haben nur untherapierte Patienten erreicht. Daraus ist zu schließen, dass auch Carrier vom frühen Therapiebeginn ab Auftreten einer Proteinurie langfristig profitieren. Durch die Therapie kann der Beginn einer terminalen Niereninsuffizienz entscheidend nach hinten verschoben werden.

Um bei der chronischen, langsam progredienten Erkrankung die Therapie über viele Jahre hinweg optimal zu gestalten, ist eine erfolgreiche Transition der Patienten notwendig, insbesondere bei dem Wechsel von der Kinder- zur Erwachsenenmedizin. Die von mir erhobenen Daten zeigen, dass die Dauer zwischen dem ersten Symptom und der endgültigen Diagnose unabhängig von dem Alter der Patienten zu lang ist, wodurch wertvolle Zeit zur präventiven Therapie verloren geht. Obwohl die Auswertung belegt, dass gerade die Mitbeteiligung des Innenohrs signifikant mit der Schwere des Krankheitsverlaufes korreliert, war dennoch bei einem Großteil der Patienten bisher keine Abklärung von extrarenalen Manifestationen erfolgt. Dabei sind regelmäßige Kontrollen und die konsequente fachärztliche Anbindung entscheidend für einen rechtzeitigen Therapiebeginn. Für die bessere Versorgung der Patienten wäre es daher in Zukunft wichtig, die in diesem Kontext wichtige Zusammenschau der Ergebnisse von Nephrologen, Augen- und Ohrenarzt zu verstärken.

Um diese Ergebnisse in der Praxis zu berücksichtigen, ist die Einbeziehung der heterozygoten Überträger im Diagnostik-Algorithmus unerlässlich. Es ist anzunehmen, dass sich bei der überwiegenden Mehrzahl der Carrier ein terminales Nierenversagen verhindern lassen könnte.

Die Ergebnisse der vorliegenden Arbeit konnten 2016 in der Zeitschrift „Pediatric Nephrology“ unter dem Titel „Prospective study on the potential of RAAS blockade to halt renal disease in Alport syndrome patients with heterosygous mutations "veröffentlicht werden. 


\section{Anhang}

\section{Alportregister Aktualisierung 2013}

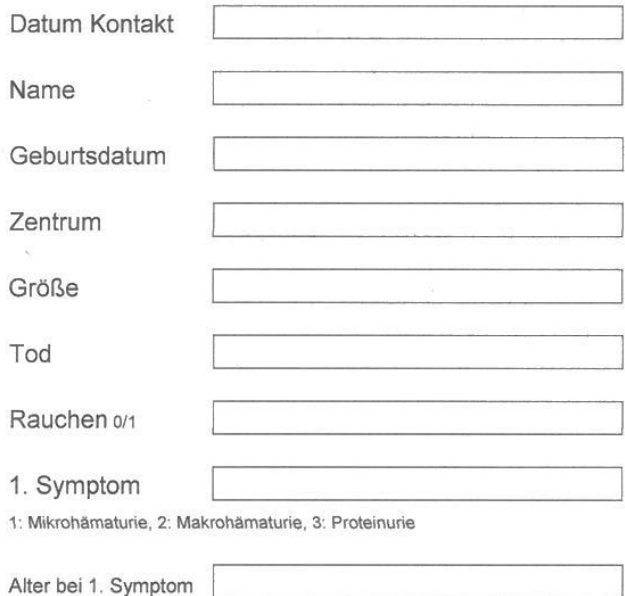

Patientennummer

Telefon/Email

Geschlecht

Familienkürzel

Gewicht

wann/ Alter

Hypertonie 0/1

Dauer 1. Symptom

bis Diagnose

\section{Diagnostik}

Biopsie 0/1

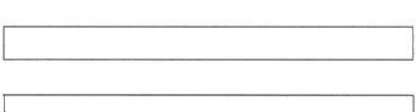

LM Diagnose

1:FSGS, 2:membranose $\mathrm{GN}$, 3.mesangioproliferative $\mathrm{GN}$, 4: minimal change

Mutation

Vererbung

Träger 0/1

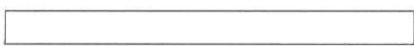

Carrier 0/1

Protein

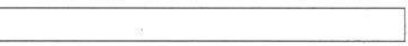

Crea

aktuelles

Stadium

0: nur Hämaturie, 1: Mikroalbuminurie 30-300mg/d, 2: Proteinurie $>300 \mathrm{mg} / \mathrm{d}, 3:$ GFR $<60 \mathrm{~m} / \mathrm{min}$,

Schwerhörigkeit

0: n.u, 1:o.p.B., 2: m.p.B.

Therapie

ACE $0 / 1$

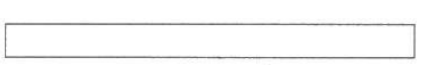

seit wann

AT1 0/1

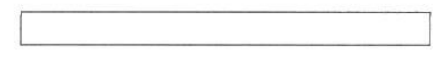

CSE $0 / 1$

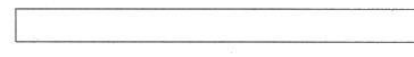

Nebenwirkungen

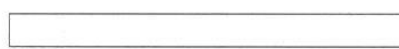

Dialyse 0/1

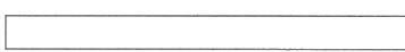

TX0/1

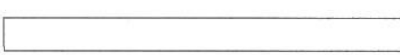

Tx Abstoßung 0/1

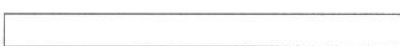

Geschwister 0/1

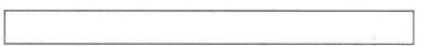

\section{seit wann}

seit wann

welche

seit wann

wann

TxFunktionsdauer

Geschwister Therapie

(früh/spät)
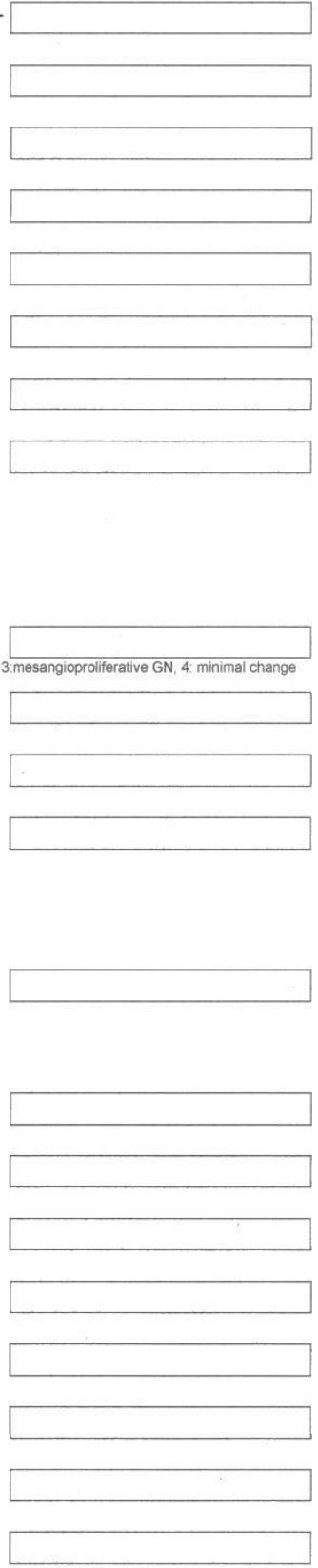

Bemerkungen

Abbildung 14: Fragebogen zur Datenerhebung 


\section{$7 \quad$ Literaturverzeichnis}

Abrahamson DR, Prettyman AC, Robert B, St John PL (2003): Laminin-1 reexpression in Alport mouse glomerular basement membranes. Kidney Int. 63, 826-834

Abrahamson DR, Isom K, Roach E, Stroganova L, Zelenchuk A, Miner JH, St John PL (2007): Laminin compensation in collagen alpha3(IV) knockout (Alport) glomeruli contributes to permeability defects. J Am Soc Nephrol 1ㄹ, 2465-2472

Abrahamson DR, Hudson BG, Stroganova L, Borza D-B, St John PL (2009): Cellular origins of type IV collagen networks in developing glomeruli. J Am Soc Nephrol. 20, 14711479

Adam J, Connor, Thomas M F, Wood K, Lewis D, Naik R, Gale DP, Sayer JA (2013): Genetic testing can resolve diagnostic confusion in Alport syndrome. Clinic Kidney J 7 , 197-200

Alport AC (1927): Hereditary familial congenital haemorrhagic nephritis. Br Med J 1, 504 506

Barczyk M, Carracedo S, Gullberg D (2010): Integrins. Cell Tissue Res 339, 269-280

Barker DF, Hostikka SL, Zhou J, Chow LT, Oliphant AR, Gerken SC, Gregory MC, Skolnick MH, Atkin CL, Tryggvason K (1990): Identification of mutations in the COL4A5 collagen gene in Alport syndrome. Science 248, 1224-1227

Choi Jh, Na Ks, Bae Sh, Roh Gh (2005): Anterior lens capsule abnormalities in Alport syndrome. Korean J Ophthalmol 19, 84-89

Churg J, Sherman RL (1973): Pathologic characteristics of hereditary nephritis. Arch Pathol 95, 374-379

Cosgrove D (2012): Glomerular pathology in Alport syndrome: a molecular perspective. Pediatr Nephrol 27, 885-890

Dagher H, Buzza M, Colville D, Jones C, Powell H, Fassett R, Wilson D, Agar J, Savige J (2001): A comparison of the clinical, histopathologic, and ultrastructural phenotypes in carriers of X-linked and autosomal recessive Alport's syndrome. Am J Kidney Dis $\underline{38}$, $1217-1228$

Daina E, Cravedi P, Alpa M, Roccatello D, Gamba S, Perna A, Gaspari F, Remuzzi G, Ruggenenti P (2015): A Multidrug, Antiproteinuric Approach to Alport Syndrome: A TenYear Cohort Study. Nephron 130, 13-20

Fawzi AA, Lee NG, Eliott D, Song J, Stewart JM (2009): Retinal findings in patients with Alport Syndrome: expanding the clinical spectrum. Br J Ophthalmol 93, 1606-1611

Flinter FA, Cameron JS, Chantler C, Houston I, Bobrow M (1988): Genetics of classic Alport's syndrome. Lancet $\underline{2}, 1005-1007$

Giani M, Mastrangelo A, Villa R, Turolo S, Marra G, Tirelli AS, Hopfer H, Edefonti A (2013): Alport syndrome: the effects of spironolactone on proteinuria and urinary TGF- $\beta 1$. Pediatr Nephrol 28, $1837-1842$

Gilbert RE, Krum H, Wilkinson-Berka J, Kelly DJ (2003): The renin-angiotensin system and the long-term complications of diabetes: pathophysiological and therapeutic considerations. Diabet Med 20, 607-621 
Gratton MA, Rao VH, Meehan DT, Askew C, Cosgrove D (2005): Matrix

Metalloproteinase Dysregulation in the Stria Vascularis of Mice with Alport Syndrome: Implications for Capillary Basement Membrane Pathology. Am J Pathol 166, 1465-1474

Gross O (2002): Meta-analysis of genotype-phenotype correlation in X-linked Alport syndrome: impact on clinical counselling. Nephrol Dial Transplant 17, 1218-1227

Gross O, Beirowski B, Koepke M-L, Kuck J, Reiner M, Addicks K, Smyth N, SchulzeLohoff E, Weber M (2003): Preemptive ramipril therapy delays renal failure and reduces renal fibrosis in COL4A3-knockout mice with Alport syndrome. Kidney Int 63, 438-446

Gross O, Beirowski B, Harvey SJ, Mcfadden C, Chen D, Tam S, Thorner PS, Smyth N, Addicks K, Bloch W (2004): DDR1-deficient mice show localized subepithelial GBM thickening with focal loss of slit diaphragms and proteinuria. Kidney Int $\underline{66}, 102-111$

Gross O, Koepke M-L, Beirowski B, Schulze-Lohoff E, Segerer S, Weber M (2005): Nephroprotection by antifibrotic and anti-inflammatory effects of the vasopeptidase inhibitor AVE7688. Kidney Int $\underline{68}$, 456-463

Gross O, Borza D-B, Anders H-J, Licht C, Weber M, Segerer S, Torra R, Gubler M-C, Heidet L, Harvey S (2009a): Stem cell therapy for Alport syndrome: the hope beyond the hype. Nephrol Dial Transplant 24, 731-734

Gross O, Weber M, Fries, Jochen W U, Müller G-A (2009b): Living donor kidney transplantation from relatives with mild urinary abnormalities in Alport syndrome: longterm risk, benefit and outcome. Nephrol Dial Transplant 24, 1626-1630

Gross O, Friede T, Hilgers R, Gorlitz A, Gavenis K, Ahmed R, Durr U (2012a): Safety and Efficacy of the ACE-Inhibitor Ramipril in Alport Syndrome: The Double-Blind, Randomized, Placebo-Controlled, Multicenter Phase III EARLY PRO-TECT Alport Trial in Pediatric Patients. ISRN Pediatr 2012, 436046

Gross O, Licht C, Anders HJ, Hoppe B, Beck B, Tonshoff B, Hocker B, Wygoda S, Ehrich JHH, Pape L (2012b): Early angiotensin-converting enzyme inhibition in Alport syndrome delays renal failure and improves life expectancy. Kidney Int $\underline{81}$, 494-501

Gross O, Kashtan CE, Rheault MN, Flinter F, Savige J, Miner JH, Torra R, Ars E, Deltas $\mathrm{C}$, Savva I (2016): Advances and unmet needs in genetic, basic and clinical science in Alport syndrome: report from the 2015 International Workshop on Alport Syndrome. Nephrol Dial Transplant

Grunfeld JP, Noel LH, Hafez S, Droz D (1985): Renal prognosis in women with hereditary nephritis. Clin Nephrol 23, $267-271$

Harvey SJ, Mount R, Sado Y, Naito I, Ninomiya Y, Harrison R, Jefferson B, Jacobs R, Thorner PS (2001): The Inner Ear of Dogs with X-Linked Nephritis Provides Clues to the Pathogenesis of Hearing Loss in X-Linked Alport Syndrome. Am J Pathol 159, 1097-1104

Hasstedt SJ, Atkin CL (1983): X-linked inheritance of Alport syndrome: family P revisited. Am J Hum Genet $\underline{35}, 1241-1251$

Hasstedt SJ, Atkin CL, San Juan, A C (1986): Genetic heterogeneity among kindreds with Alport syndrome. Am J Hum Genet $\underline{38}$, 940-953

Hertz JM (2009): Alport syndrome. Molecular genetic aspects. Dan Med Bull 56, 105-152

Hertz JM, Thomassen M, Storey H, Flinter F (2012): Clinical utility gene card for: Alport syndrome. Eur J Hum. Genet. $\underline{20}$ 
Hinglais N, Grunfeld JP, Bois E (1972): Characteristic ultrastructural lesion of the glomerular basement membrane in progressive hereditary nephritis (Alport's syndrome). Lab Invest $\underline{27}, 473-487$

Hudson BG (2004): The molecular basis of Goodpasture and Alport syndromes: beacons for the discovery of the collagen IV family. J Am Soc Nephrol 15, 2514-2527

Hudson BG, Reeders ST, Tryggvason K (1993): Type IV collagen: structure, gene organization, and role in human diseases. Molecular basis of Goodpasture and Alport syndromes and diffuse leiomyomatosis. J Biol Chem 268, 26033-26036

Hudson BG, Tryggvason K, Sundaramoorthy M, Neilson EG (2003): Alport's Syndrome, Goodpasture's Syndrome, and Type IV Collagen. N Engl J Med 348, 2543-2556

Hurst AF (1923): Hereditary familial congenital haemorrhagic nephritis occurring in sixteen individuals in three generations. Guy's Hosp Rec, 368-370

Jais JP, Knebelmann B, Giatras I, Marchi M de, Rizzoni G, Renieri A, Weber M, Gross O, Netzer KO, Flinter F et al.(2000): X-linked Alport syndrome: natural history in 195 families and genotype- phenotype correlations in males. J Am Soc Nephrol 11, 649-657

Jais JP, Knebelmann B, Giatras I, Marchi M de, Rizzoni G, Renieri A, Weber M, Gross O, Netzer KO, Flinter F et al.(2003): X-Linked Alport Syndrome: Natural History and Genotype-Phenotype Correlations in Girls and Women Belonging to 195 Families: A "European Community Alport Syndrome Concerted Action" Study. J Am Soc Nephrol 14, 2603-2610

Kaito H, Nozu K, Iijima K, Nakanishi K, Yoshiya K, Kanda K, Przybyslaw Krol R, Yoshikawa N, Matsuo M (2006): The effect of aldosterone blockade in patients with Alport syndrome. Pediatr Nephrol 21, 1824-1829

Kalluri R, Shield CF, Todd P, Hudson BG, Neilson EG (1997): Isoform switching of type IV collagen is developmentally arrested in X-linked Alport syndrome leading to increased susceptibility of renal basement membranes to endoproteolysis. J Clin Invest 99, 2470_ 2478

Karow T, Lang-Roth R: Allgemeine und Spezielle Pharmakologie und Toxikologie, 20.Auflage; Thomas Karow (Verlag), Pulheim 2012

Kashtan CE (1999): Alport syndrome. An inherited disorder of renal, ocular, and cochlear basement membranes. Medicine (Baltimore) $\underline{78}$, 338-360

Kashtan CE (2006): Renal transplantation in patients with Alport syndrome. Pediatr Transplant $\underline{10}$, 651-657

Kashtan CE, Ding J, Gregory M, Gross O, Heidet L, Knebelmann B, Rheault M, Licht C (2013): Clinical practice recommendations for the treatment of Alport syndrome: a statement of the Alport Syndrome Research Collaborative. Pediatr Nephrol 28, 5-11

Koepke M-L, Weber M, Schulze-Lohoff E, Beirowski B, Segerer S, Gross O (2007): Nephroprotective effect of the HMG-CoA-reductase inhibitor cerivastatin in a mouse model of progressive renal fibrosis in Alport syndrome. Nephrol Dial Transplant 22, 10621069

Korbet SM (2002): Treatment of primary focal segmental glomerulosclerosis. Kidney Int $\underline{62}, 2301-2310$

Kruegel J, Rubel D, Gross O (2013): Alport syndrome--insights from basic and clinical research. Nat Rev Nephrol $\underline{9}, 170-178$ 
Liu Y (2010): New insights into epithelial-mesenchymal transition in kidney fibrosis. J Am Soc Nephrol 21, 212-222

Massella L, Muda AO, Faraggiana T, Bette C, Renieri A, Rizzoni G (2003): Epidermal basement membrane $\alpha 5$ (IV) expression in females with Alport syndrome and severity of renal disease. Kidney Int 64, 1787-1791

Meroni M, Sessa A (2013): Orphanet-Alport-Syndrom. http://www.orpha.net/consor/cgibin/OC_Exp.php?Lng=DE\&Expert=63 Zugriff am 19.11.2017

Miner JH (1999): Renal basement membrane components. Kidney Int 56, 2016-2024

Morinière V, Dahan K, Hilbert P, Lison M, Lebbah S, Topa A, Bole-Feysot C, Pruvost S, Nitschke P, Plaisier E (2014): Improving Mutation Screening in Familial Hematuric Nephropathies through Next Generation Sequencing. J Am Soc Nephrol 25, 2740-2751

Noone D, Licht C (2013): An update on the pathomechanisms and future therapies of Alport syndrome. Pediatr Nephrol 28, 1025-1036

Oka M, Nozu K, Kaito H, Fu XJ, Nakanishi K, Hashimura Y, Morisada N, Yan K, Matsuo M, Yoshikawa N (2014): Natural history of genetically proven autosomal recessive Alport syndrome. Pediatr Nephrol 29, 1535-1544

Pajari H, Kääriäinen H, Muhonen T, Koskimies O (1996): Alport's syndrome in 78 patients: epidemiological and clinical study. Acta Pædiatrica 85, 1300-1306

Prockop DJ (1990): Mutations that alter the primary structure of type I collagen. The perils of a system for generating large structures by the principle of nucleated growth. J Biol Chem 265, 15349-15352

Prockop DJ (1995): Collagens: Molecular Biology, Diseases, and Potentials for Therapy. Annu Rev Biochem 64, 403-434

Rana K (2005): The Genetics of Thin Basement Membrane Nephropathy. Semin Nephrol $\underline{25}, 163-170$

Remuzzi G, Perico N, Macia M, Ruggenenti P (2005): The role of renin-angiotensinaldosterone system in the progression of chronic kidney disease. Kidney Int Suppl, S57-65

Savige J, Rana K, Tonna S, Buzza M, Dagher H, Wang YY (2003): Thin basement membrane nephropathy. Kidney Int 64, 1169-1178

Savige J, Liu J, DeBuc DC, Handa JT, Hageman GS, Wang YY, Parkin JD, Vote B, Fassett R, Sarks S (2010): Retinal Basement Membrane Abnormalities and the Retinopathy of Alport Syndrome. Invest Ophthalmol Vis Sci $\underline{51}, 1621-1627$

Savige J, Gregory M, Gross O, Kashtan C, Ding J, Flinter F (2013): Expert Guidelines for the Management of Alport Syndrome and Thin Basement Membrane Nephropathy. J Am Soc Nephrol 24, 364-375

Sayers R, Kalluri R, Rodgers KD, Shield CF, Meehan DT, Cosgrove D (1999): Role for transforming growth factor-beta1 in alport renal disease progression. Kidney Int $\underline{56}, 1662$ 1673

Shaw EA, Colville D, Wang YY, Zhang KW, Dagher H, Fassett R, Guymer R, Savige J (2007): Characterization of the peripheral retinopathy in $X$-linked and autosomal recessive Alport syndrome. Nephrol Dial Transplant 22, 104-108

Siragy HM, Carey RM (2010): Role of the intrarenal renin-angiotensin-aldosterone system in chronic kidney disease. Am J Nephrol $\underline{31}, 541-550$ 
Stock J, Kuenanz J, Glonke N, Gross O (2015): Potential of raas-blockade to halt renal disease in heterozygous carriers of alport-mutations: a 4-year prospective study. Nephrol Dial Transplant $\underline{30}$

Stock J, Kuenanz J, Glonke N, Sonntag J, Frese J, Tönshoff B, Höcker B, Hoppe B, Feldkötter M, Pape L (2017): Prospective study on the potential of RAAS blockade to halt renal disease in Alport syndrome patients with heterozygous mutations. Pediatr nephrol $\underline{32}$

Tan R, Colville D, Wang YY, Rigby L, Savige J (2009): Alport Retinopathy Results from "Severe" COL4A5 Mutations and Predicts Early Renal Failure. Clinic J Am Soc Nephrol $\underline{5}$, 34-38

Temme J, Peters F, Lange K, Pirson Y, Heidet L, Torra R, Grunfeld J-P, Weber M, Licht C, Muller G-A (2012): Incidence of renal failure and nephroprotection by RAAS inhibition in heterozygous carriers of X-chromosomal and autosomal recessive Alport mutations. Kidney Int $\underline{81}, 779-783$

Tryggvason K, Patrakka J (2006): Thin basement membrane nephropathy. J Am Soc Nephrol 17, 813-822

Vogel W, Gish GD, Alves F, Pawson T (1997): The discoidin domain receptor tyrosine kinases are activated by collagen. Mol Cell $\underline{1}, 13-23$

Wang Y, Sivakumar V, Mohammad M, Colville D, Storey H, Flinter F, Dagher H, Savige J (2014): Clinical and genetic features in autosomal recessive and X-linked Alport syndrome. Pediatr Nephrol 29, 391-396

Webb NJA, Lam C, Shahinfar S, Strehlau J, Wells TG, Gleim GW, Le Bailly De Tilleghem C (2011): Efficacy and safety of losartan in children with Alport syndrome--results from a subgroup analysis of a prospective, randomized, placebo- or amlodipine-controlled trial. Nephrol Dial Transplant 26, 2521-2526

Yamasoba T, Lin FR, Someya S, Kashio A, Sakamoto T, Kondo K (2013): Current concepts in age-related hearing loss: epidemiology and mechanistic pathways. Hear Res $\underline{303}, 30-38$

Yao X-d, Chen X, Huang G-y, Yu Y-t, Xu S-t, Hu Y-l, Wang Q-w, Chen H-p, Zeng C-h, Ji D-x (2012): Challenge in pathologic diagnosis of Alport syndrome: evidence from correction of previous misdiagnosis. Orphanet J Rare Dis $\underline{7}, 100$

Zeisberg M, Bottiglio C, Kumar N, Maeshima Y, Strutz F, Muller GA, Kalluri R (2003):

Bone morphogenic protein-7 inhibits progression of chronic renal fibrosis associated with two genetic mouse models. Am J Physiol Renal Physiol 285, F1060-7

Zeisberg M, Khurana M, Rao VH, Cosgrove D, Rougier J-P, Werner MC, Shield, Charles F 3rd, Werb Z, Kalluri R (2006): Stage-specific action of matrix metalloproteinases influences progressive hereditary kidney disease. PLoS Med $\underline{3}$, e100

Zhang X, Zhou J, Reeders ST, Tryggvason K (1996): Structure of the Human Type IV CollagenCOL4A6Gene, Which Is Mutated in Alport Syndrome-Associated Leiomyomatosis. Genomics $\underline{33}$, 473-479 


\section{Danksagung}

Ich möchte Prof. Dr. med. O. Gross für die Bereitstellung des Themas und ihmzusammen mit Dr. med. Johanna Stock- für die Betreuung und die stets rasche Beantwortung meiner Fragen ganz herzlich danken. Die konstruktive Kritik und die jederzeit unkomplizierte Kontaktaufnahme waren sehr hilfreich und für das Fortschreiten der Arbeit unabdingbar.

Des Weiteren gilt Frau Frauke Weber ein großer Dank für die Unterstützung bei der Kontaktaufnahme zu den bundesweiten Alportzentren.

Ebenfalls danke ich der medizinischen statistischen Abteilung der Universität Göttingen für die zielführende Beratung und Hilfe bei statistischen Fragestellungen.

Ein großer Dank gilt zudem Lucia Eder für die Unterstützung während des gesamten Arbeitsprozesses und Elisabeth Eder-Gerke für die kompetente Unterstützung bei der formalen Korrektur. 